\title{
Regulation of network infrastructure investments: an experimental evaluation
}

\author{
Bastian Henze · Charles Noussair • Bert Willems
}

(C) The Author(s) 2012. This article is published with open access at Springerlink.com

\begin{abstract}
This paper reports the results of an experiment evaluating three regulatory schemes for network infrastructure, in terms of their ability to generate efficient levels of capacity investment. We compare the performance of (1) price cap regulation, (2) a regulatory holiday for new capacity, and (3) price cap regulation with long term contracts combined with a secondary market. The setting is one in which network users can benefit from acting strategically, and are better informed than the network operator about demand growth. We find that the regulatory holiday creates an incentive to underinvest relative to optimal levels. Long term contracts also fail to improve on single price-cap regulation, and may reduce investment by providing noisier signals about future demand.
\end{abstract}

Keywords Infrastructure investment $\cdot$ Experiment $\cdot$ Price cap $\cdot$ Regulatory holiday

JEL Classification C9 $\cdot$ L51 $\cdot$ L95

B. Henze · B. Willems $(\bowtie)$

Department of Economics, Tilec, CentER, Tilburg University, P.O. Box 90153, 5000 LE Tilburg,

The Netherlands

e-mail: bwillems@tilburguniversity.edu

B. Henze

e-mail: bastian.henze@googlemail.com

C. Noussair

Department of Economics, CentER, Tilburg University, P.O. Box 90153, 5000 LE Tilburg,

The Netherlands

e-mail: c.n.noussair@tilburguniversity.edu 


\section{Introduction}

Some types of network infrastructure, such as gas pipelines and electricity grids, are characterized by natural monopoly, irreversible investment in capacity, and a lack of vertical integration between network operator and user. The sub-additive cost structure of these networks necessitates access regulation to prevent the network operator from exploiting its market power. In the European Union, the typical approach is to impose incentive regulation in the form of price or revenue caps. ${ }^{1}$ Cap regulation creates an incentive for the network operator to reduce its marginal costs, but it provides weak incentives to expand capacity, and can decrease the expected profitability of additional capacity (Vogelsang 2010). ${ }^{2}$

Several regulatory schemes exist with the specific purpose of addressing underinvestment in such industries. Under a Regulatory Holiday (see e.g. Gans and King 2003), a firm undertaking an investment is exempted from regulation of the profits from the investment, for a pre-specified period of time. A regulatory holiday has the advantages that it is easy for authorities to commit to, and carries no cost of enforcement. It increases the expected profit from a new investment, compensating the network operator for the risk of low future demand, and thereby can create an incentive to increase capacity. ${ }^{3}$ However, the regulatory holiday may also incentivize the network operator to withhold or delay capacity expansion, in order to exploit potential monopoly pricing power.

Another approach to encourage infrastructure investment is to reduce the investor's risk by improving its information about future demand for access to its network. A market for forward contracts for network access can potentially provide this information. There are other potential advantages of forward contracting. It decouples the network operator's income from potentially volatile spot market revenues. Network users can use the contracts to hedge against shortages and high spot market prices. Inclusion of a forward market might also cause the spot market

\footnotetext{
1 Within the European Union, regulatory policies vary by country, by industry, and can differ between transmission and distribution. Furthermore, prices or revenue may be capped. For new investment in electricity distribution networks, France, Germany, and the UK use a revenue cap, while Italy employs a mix of price cap and rate of return, and Spain has a hybrid between revenue cap and rate-of-return regulation (Eurelectric, 2010), For gas distribution, revenue or price capping is employed in all five countries, having been adopted in 2009 in Germany and 2011 in France. For both electricity and gas transmission, rate of return regulation is applied in France, while capping is used in the UK, Germany, France and Spain. The regulatory system we use in the paper as our Baseline is a price cap on capital costs. In our environment with constant marginal cost, it is equivalent to rate-of-return regulation with an ex-post used-and-useful rule.

2 In the European Union, there is a particular need for investment in the gas pipeline network because of growing demand for natural gas. Around 200 Billion Euro must be invested in the energy transport networks (gas and electricity) by 2020 (MEMO/10/582).

3 The European Union (2003) has provisions for regulatory holidays for electricity and gas networks. The Second Gas Market Directive (2003/55/EC, Article 22) allows the granting of a regulatory holiday for investors establishing new pipeline capacity, albeit under strict conditions. Sometimes only partial exemptions are given (ERGEG 2008). A total of 13 exemptions for LNG terminals and interconnectors have been granted (ERGEG 2009).
} 
to become more competitive, because of arbitrage between the spot and forward markets.

We consider here a special type of forward contract called a Long-Term Financial Transmission Right or LTFTR (Hogan 1992; Bushnell and Stoft 1996; Hogan et al. 2010). A network user holding such a contract receives a payment equal to the spot price for each access right unit, regardless of whether or not she obtains units on the spot market. ${ }^{4}$ In the implementation we study, the LTFTR are allocated with a uniform price sealed bid auction. The use of an auction, in addition to its presumed tendency to allocate the contracts to the most highly valued users, has the feature that it yields an array of bids to the seller that may give her useful information about the future demand she faces. ${ }^{5}$

We construct a laboratory experimental environment to evaluate the performance of a regulatory holiday, and a system of forward contracting in the form of auctions of LTFTR, against a baseline of price cap regulation. The criteria for evaluation are investment and welfare levels. We compare the regulatory schemes to each other and to several simulated benchmarks: the social optimum, the behavior of an unregulated monopolist, and the decisions of a profit-maximizing firm acting within each scheme. We also compare prices, and the relative share of the surplus that network operators, users, and the regulating authority receive, among the three systems.

The literature on price caps and related incentives concentrates almost exclusively on the relationship between regulators and network operators, and reduces the role of network users to perfectly competitive, rational, fully informed price takers. Our experimental approach allows us to relax these assumptions and to study the complex, and possibly boundedly rational, interactions between network operator and users. We point out how questionable the assumption of price-taking on the part of demanders is, and we conclude that buyer behavior should be modeled more realistically, and taken into account in any proposed regulatory mechanism. This is particularly relevant in the energy transmission market, where the small number of buyers are themselves load-serving entities.

The paper is organized as follows. Section 2 provides an overview of the relevant literature. Section 3 describes the experimental design while Sect. 4 presents the results from simulations that serve as our source for null hypotheses. In Sect. 5 we present and analyze our results. Section 6 concludes.

\footnotetext{
4 In the gas market, capacity contracts often come with a "use-it-or-lose-it" rule. If a user purchases capacity but does not use it, it still has to pay for it, and the unused capacity will be sold by the network operator to other network users. This contract feature prevents network users from strategically withholding network capacity. Joskow and Tirole (2000) show that a financial transmission right is strategically equivalent to a physical transmission right with a use-it-or-lose-it condition.

5 The auction uses lowest-accepted-bid pricing in an environment in which all bidders have multi-unit demand. While the auction is not incentive compatible (see for example Draaisma and Noussair 1997), experiments show that the ordering of the bidding array tends to reflect rather well the ordering of the underlying valuations, resulting in high allocative efficiency (Alsemgeest et al. 1998).
} 


\section{Policy issues and related literature}

\subsection{Policy issues}

Under traditional rate-of-return regulation, rates are set to guarantee that firms recover their investment cost. This has led to concerns that firms might overinvest (Averch and Johnson 1962) or exert too little effort to lower cost, leading to "x-inefficiencies". As a result, regulators, especially in Europe, often opt for incentive regulation, typically by setting a price cap. Under a price cap regime, firms do have strong incentives to reduce cost. ${ }^{6}$ Indeed, Cambini and Rondi (2010) show that investment levels by European energy companies in cost reduction are greater under incentive regulation than under rate-of-return regulation. However incentives to undertake durable sunk investments in new capacity are weak, especially when future demand is very uncertain. ${ }^{7}$ Network operators face a large downside risk if an investment turns out to unprofitable, but cannot reap the full upside benefit if it is profitable. Price cap regulation does not take into account the real option value of investments, and thus the timing of new investments might also not be optimal (Guthrie 2006). ${ }^{8}$

Gans and King (2004) describe how Regulatory Holidays can reduce these problems, if the duration of the regulatory holidays is appropriately chosen. Spanjer (2008) points out that while Regulatory Holidays can alleviate underinvestment, they can distort the timing of investments away from the optimum. Nagel and Rammerstorfer (2008) propose enhancing price cap regulation with revenue sharing, in order to improve the timing of investments. Under their system, the price cap does not apply for a portion of the installed capacity. Similarly, Vogelsang (2010) advocates regulatory holidays only for truly innovative investments. ${ }^{9}$ In our implementation, the regulatory holiday applies for newly built capacity by the incumbent network operator; while old capacity remains regulated. We allow the network operator to withhold capacity from the market. ${ }^{10}$

An LTFTR is a financial forward contract on network capacity. It is well known that forward contracts can have beneficial effects on competition in some theoretical models. For instance, forward markets improve competition in Cournot (Allaz and Vila

\footnotetext{
6 It is often argued that incentive regulation lowers the informational requirements for the regulator. Joskow (2005) suggests that this might not be the case in electricity networks.

7 In their excellent review, Armstrong and Sappington (2007) give an overview of various aspects in which rate of return and price cap regulation might differ.

8 Cambini and Yiang (2009) review the evidence linking incentive regulation and investments.

9 Rosellón (2003) discusses three regulatory policies for electricity network investments and the possible hurdles for implementing them in practice. Two of these policies roughly correspond to two of our experimental treatments. One is a system of long-term financial transmission rights, as we implement in our forward auction treatment. The second is a system where regulation attempts to take into account the real option value of investments, as in our "regulatory holiday" treatment. The third is incentive regulation (see also Léautier 2000), of which price cap regulation is a special case. Hogan et al. (2010) combine a Long Term Financial Transmission Rights system with Vogelsang (2001) system of incentive regulation, in an attempt to combine the advantages of both systems.

10 Brunekreeft and Newbery (2005) show that imposing a must-serve obligation on a merchant investor, who is subject to a regulatory holiday, would reduce investment and welfare in most cases.
} 
1993) and supply function bidding (Holmberg 2011) games. Long term transportation rights, similar to LTFTRs, have been in use for allocating network infrastructure in the American gas market. Furthermore, Bushnell and Stoft $(1996,1997)$ show how Financial Transmission Rights (FTRs) could be used in the US electricity sector to decentralize investment decisions. The long term rights to capacity give merchant investors an incentive to build additional pipeline capacity (Kristiansen and Rosellón 2006). Joskow and Tirole (2005), however, argue that such a system cannot easily be implemented in the American electricity sector because of its inherent complexities.

Energy network services are separated by law from energy commodities, and this vertical separation is called unbundling. ${ }^{11}$ There is an ongoing debate about whether unbundling itself, independently of the type of regulation, leads to underinvestment (see Cremer et al. 2006; von Hirschhausen 2008). Long-term contracting can be viewed as a substitute for vertical integration, because it allows internalization of the externalities from investments. It may be particularly suitable for energy markets, which have a few large users, since relatively few contracts would need to be made. In our paper we impose unbundling and completely separate the network operator and users.

\subsection{Previous related experimental work}

Experimental methods have been applied to various economic issues arising in network industries. Important early contributions include work on the allocation of airport landing slots (Grether et al. 1981) and gas pipelines (McCabe et al. 1989, 1990). See Staropoli and Jullien (2006) for a survey of experiments focused on electricity markets, and Normann and Ricciuti (2009) for a survey of experimental work on economic policy issues.

Some studies have considered the behavior of auctions in experimental environments modeled on electricity markets. Rassenti et al. (2003a) find that demand side bidding on a spot market is an effective way to discipline the pricing behavior of a network operator. Furthermore, Rassenti et al. (2003b) find that the uniform price auction leads to more efficient allocations in an experimental electricity market than a discriminatory auction. These results have influenced our choice to have the market price and allocation determined by a demand-side uniform price auction, since we seek to minimize the inefficiency that results from the market trading rules. ${ }^{12}$

There have been some previous studies of forward contracting in markets. For example, Krogmeier et al. (1997) and Phillips et al. (2001) compare markets in which production can occur in response to demand, which is in essence a forward market, to those in which production must occur in advance. Le Coq and Orzen (2006) construct

\footnotetext{
11 In the E.U., regulations No. 2009/72/EC and 2009/73/EC impose unbundling in the gas and electricity markets. FERC order No. 636 (1992) imposes similar measures for intrastate pipelines in the U.S. In the telecommunication sector, network owners are also active downstream, which affects their investment incentives. See Klumpp and Su (2010) for an analysis of the investment incentives of a vertically integrated firm that is subject to revenue neutral open access regulation.

12 A sizable experimental literature has considered the properties of different auction rules for generators making offers to sell electricity to a power grid (see for example Denton et al. 2001; Abbink et al. 2003; Vossler et al. 2009).
} 
an experimental environment with an explicit forward market structure. All three studies find that the forward market, operating alone, has lower prices, greater quantity traded and greater efficiency than a spot market operating alone. Brandts et al. (2008) find that for both quantity and supply function competition, the addition of a forward market to a spot market lowers prices and increases production. These findings suggest that a forward market might be effective in allocating existing capacity in our setting.

Kench (2004) conducts the only experiment, of which we are aware, that investigates financial transmission rights. He compares their performance to a system of physical rights, in a setting in which network users obtain a random initial allocation of rights, and then can trade them with other users. This differs from our setting, where users buy rights from the network operator. He finds that physical rights outperform financial rights in terms of providing accurate market signals. ${ }^{13}$ In a setting with financial rights, generators are less active in the transmission rights market, as they still have the option to wait, and trade energy in the spot market. Furthermore, network users that were unable to procure financial transmission rights and are therefore unhedged, bid strategically in the spot market and lower the overall efficiency of the market system. These results suggest the presence of LTFTR's might change spot market bidding in our setting. In particular, holders of LTFTR might bid high prices for capacity in the spot market because they are insured against high prices. On the other hand, those without LTFTR may tend to strategically underbid, with the effect of lowering prices.

There are two experimental studies that focus specifically on investment in supply capacity in energy markets. They consider the generation and supply of energy rather than the transport of energy as we do here. Kiesling and Wilson (2007) find that an automated mitigation procedure (AMP), which has been proposed as an alternative to a price cap, does not decrease investment in capacity relative to a setting in which prices are unregulated. Williamson et al. (2006) find that investment, in an unregulated oligopoly, is close to the Cournot-Nash level on average, with some distortion in the mix between marginal and baseload capacities. These two studies differ from ours in many respects, but perhaps most fundamentally in that they study oligopolies, in contrast to the monopoly setting that is of interest to us.

\section{Experimental design and procedures}

The experiments took place in 12 sessions conducted at CentERlab at Tilburg University. The experiment was computerized and used the Ztree platform (Fischbacher 2007). There were four sessions conducted under each of three treatments. Eight subjects were recruited for each session using an online recruiting system. All participants were undergraduate students at Tilburg University, with the majority from the School of Economics and Management. After the instructions were read out aloud, subjects had the opportunity to ask questions and subsequently participated in a paper and

\footnotetext{
13 In contrast to our paper, Kench (2004) considers the auctioning of two complimentary goods: the commodity that is being traded, electricity, and the transportation capacity, access to the transmission line. We consider only the market for transportation capacity. Kench also distinguishes three types of network users: buyers of electricity, producers of electricity upstream from the congested line, and produces downstream from the congested line.
} 
pencil quiz. The quiz consisted of questions and calculation-exercises designed to test the subjects' understanding of the experiment's proceedings and market institutions. The quiz took about 10 minutes to complete. Subjects were made aware that the parameters used in the calculation exercises were not indictative of those to be encountered during the experiment. The experimenter then checked the answers, handed the quizsheets back to the subjects and discussed the correct answers. The three subjects with the greatest number of mistakes were then informed that they could not participate in the experiment and were paid 10 Euro for their participation. Of the remaining five subjects, the best-performing one was assigned to the role of network operator while the remaining four were network users.

Subjects participated in three independent sequences of periods. Initially, there was a twelve period training sequence which did not count toward participants' earnings, followed by two 30 period sequences which did count. The data from the last 30-period sequence is used for the analysis in this paper. Sessions lasted from 3-3.5 hours. The instructions and the quiz took on average between 60 and 75 minutes. ${ }^{14}$

In our experiment, the regulator is passive, and does not adjust policy based on prior activity. The regulatory schemes are exogenously imposed, and implemented with complete certainty. Regulator revenue is not rebated to participants and is thus assumed to be spent outside this sector. Our design allows the regulatory regimes to be compared ceteris parabus, and a focus on the interaction of network operator and user.

\subsection{The environment}

Aggregate Demand in each period $t$ is of the form:

$$
D_{t}=a-\frac{2 b}{g_{t}} q_{t}
$$

where $a$ and $b$ are constants, $q_{t}$ is the quantity of the product, access to the network offered by the network operator, and $g_{t}$ is a growth parameter. The inverse demand is calculated by evaluating (1) for $q_{t} \in[0,23]$ and rounding to the closest multiple of 10. ${ }^{15}$ Individual demand is private information.

Access to the network is supplied by a single network operator. In order to supply a unit of the product, the network operator must possess a sufficient quantity of network

\footnotetext{
14 While this experiment is very complex from the point of view of participants relative to many other experiments, it is less so than some other paradigms that members of the same subject pool have participated in (see for example Noussair et al. 2011). To allow for learning the task, we use only the last horizon in our data analysis. The length of each session, 3 - 3.5 hours, is long in comparison to most other studies, but we have successfully implemented other experiments that exceed four hours. To incentivize participants over this relatively long period of time, subject payments were substantial. They averaged 30.45 Euro (1 Euro $=$ US\$1.38) for network operators and 23.61 Euro for users in the baseline treatment. The comparable figures are 34.25 for operators and 21.65 for users in the Regulatory Holiday treatment, and 30.94 for operators and 24.31 for users under Forward Auction.

15 Figure A1.1 in the Appendix indicates the demand realization for each of the 30 periods of the experiment and also illustrates the time profile of $g_{t}$.
} 
capacity. For each unit of network capacity, one unit of the product can be sold in each period. The installation of additional network capacity itself is costless for the operator, but each unit of network capacity imposes a cost of $c$ ECU (experimental currency units) in each period, regardless of whether it was actually used to provide a unit of the product or not. ${ }^{16}$ Network capacity cannot be dismantled once it has been installed. There is no depreciation or scrap value for capacity. The total capacity of the network in period $t$ is designated as $K_{t}$, and the initial network capacity as $K_{0}$. The irreversibility of investment means that $K_{t} \geq K_{t-1}$ for all $t$.

\subsection{The spot market}

In each period, the product is allocated by means of a uniform-price sealed-bid auction with lowest-accepted-bid pricing. Network users can submit one bid for each one of their valuations. The network operator then decides how many units of the product it offers. If the operator offers $q$ units of the product, the $q$ highest bids are accepted and the $q$-th highest bid sets the market price $p$ for the current period. All units of the product are sold at this market price. A price cap of $p^{c a p} \mathrm{ECU}$ is in effect. If the market price exceeds the cap, the operator receives $p^{c a p} \mathrm{ECU}$ per unit of the product while network users pay the market price $p$. The resulting difference is kept by the experimenter and can be thought of as transferred to the regulating authority. ${ }^{17}$ Figure 1 shows the rents that each of the three parties receive when $q$ units are sold in a period. The dotted line shows the revealed demand implied by the bids in the auction. The area between $c$ and $p^{c a p}$ and 0 to $q$, defines a rectangle that indicates the profit to the network operator equal to $\left(p^{c a p}-c\right) \cdot q$. The rectangle immediately above indicates the revenue to the regulator of $\left(p-p^{c a p}\right) \cdot q$. The darkened region above that is the consumer surplus accruing to the users.

\subsection{Timing of activity and parameters}

The 30 periods are divided into five six-period "blocks". At the beginning of the first period of each block, the four network users learn their individual demand for each period in the current block. The users can then choose to increase the valuations from their initial level for their first two units by either the fixed value $\kappa_{L O W}$, another fixed

\footnotetext{
16 The per-period cost $c$ can be seen as the leasing cost or rental price of network capacity. We use this framing, instead of a lump-sum capacity cost, because it allows subjects to compare capital costs and revenues more easily, and avoids the need to impose a scrap value for the last period of the experiment.

17 We do not induce any framing for the subjects concerning where the revenue is directed. In our exposition here, we designate it as "government/regulating-authority revenue" and include it in the calculation of total welfare. The use of an auction corresponds with E.U. Regulation 1228/2003 which imposes a market-based allocation mechanism for cross-border network capacity and forbids for instance "first come, first serve" rationing. Regulation 1228/2003 also limits the auction revenues the network operator can receive, in order to prevent it from making too little capacity available. By allowing the prices paid by the users and the capped price received by the operator to differ, we avoid non-price rationing. Non-price rationing would decouple a user's profit from its bidding strategy to some extent; users' bids might consequently be less informative about the underlying demand.
} 
Fig. 1 Price cap regulation (B)

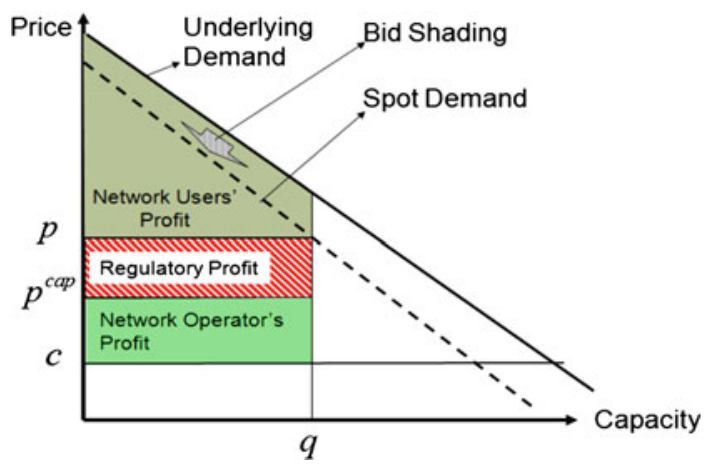

value $\kappa_{H I G H}$, or 0 , for all periods in the current block. To do so, they incur per-period costs of $\gamma_{L O W}, \gamma_{H I G H}$, or 0 , respectively. ${ }^{18}$ Figure A1.2 in the Appendix provides an illustration of the valuations under the assumption that all users raise their valuations by $\kappa_{H I G H}$.

In the first and the fourth period of each block, that is, in every third period beginning in period 1 , the network operator decides whether or not to increase the capacity of the network. The maximum amount of additional capacity which can be installed at each of these opportunities is $\triangle K^{M A X}$. The operator makes its decision prior to the spot auction of the current period. Network users are informed of any changes in network capacity before they submit their bids in the spot auction. Table 1 provides the values for all parameters discussed in this section. The choices of parameter values are explained in Appendix C.

\subsection{Treatments}

There were three treatments, Baseline (B), Regulatory Holiday (RH), and Forward Auction (FA). Sections 3.1-3.3 described the Baseline treatment. The next two subsections indicate the differences between the Baseline and the other two treatments.

\subsubsection{Regulatory holiday $(R H)$}

In the RH treatment, sales of newly installed capacity are exempt from the price cap. Thus, we in effect implement our regulatory holiday as in Nagel and Rammerstorfer (2008). We tax the difference between the market price and the price cap on old capac-

\footnotetext{
18 This opportunity to increase one's valuations is meant to represent the take-or-pay contracts that are common in Europe. These are contracts that provide a network user, typically a gas company, with the opportunity to make a long-term contract with an upstream supplier. These contracts are lucrative but also costly to break by failing to take delivery of the contracted quantity. This leads to greater valuations for the corresponding units of network capacity. The cost to users of increasing these valuations represents the various costs of concluding such a contract and the penalty that one incurs if the contracted quantity is not exchanged. We added this feature of the market, as discussions with stakeholders indicated that it was an essential feature of European gas markets.
} 
Table 1 Parameters

\begin{tabular}{lcl}
\hline Parameter & Value & Description \\
\hline$a$ & 80 & Intercept parameter in aggregate demand function \\
$b$ & 5 & Slope parameter in aggregate demand function \\
$c$ & 10 & Per period cost for one unit of network capacity \\
$p^{c a p}=f^{c a p}$ & 15 & Price Cap \\
$\kappa_{L O W}$ & 20 & Low optional increase of the highest two valuations of a network user \\
$\kappa_{H I G H}$ & 40 & High optional increase of the highest two valuations of a network user \\
$\gamma_{L O W}$ & 10 & Per period cost for raising highest two valuations by $\kappa_{L O W}$ \\
$\gamma_{H I G H}$ & 20 & Per period cost for raising highest two valuations by $\kappa_{H I G H}$ \\
$K_{0}$ & 4 & Initial network capacity \\
$\Delta K^{M A X}$ & 5 & Maximum possible investment at each investment opportunity
\end{tabular}

Fig. 2 Regulatory holiday $(\mathrm{RH})$

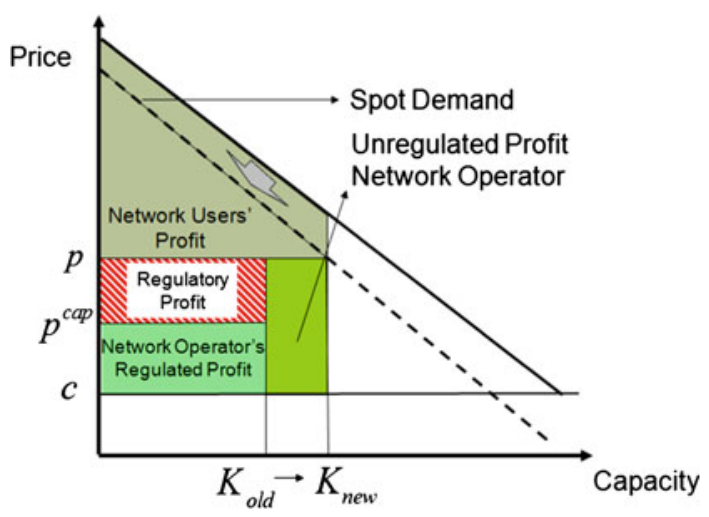

ity, but exempt newly built capacity from the tax. The RH treatment differs from the Baseline treatment only with regard to the number of product units to which the price cap is applied in the spot market. The price cap is suspended for those units of capacity that were added in the current six-period block. The suspension lasts until the onset of the subsequent six-period block.

The payoff structure in RH is illustrated in Fig. 2. The figure shows that the units between $K_{\text {old }}$ and $K_{\text {new }}$ are not subject to the price cap. The regulator revenue is equal to $\left(p-p^{c a p}\right) \cdot K_{\text {old }}$ and the profits to the network operator equal $\left(p^{c a p}-c\right) \cdot K_{\text {old }}+$ $(p-c) \cdot\left(K_{\text {new }}-K_{\text {old }}\right)$.

\subsubsection{Forward auctioning (FA)}

In the FA treatment, an auction for LTFTR is conducted in the first period of each six period block. The auction takes place after the network users have been informed about their valuations, but prior to their decision about whether to increase their valuations and prior to the network operator's decision to install additional network capacity. 

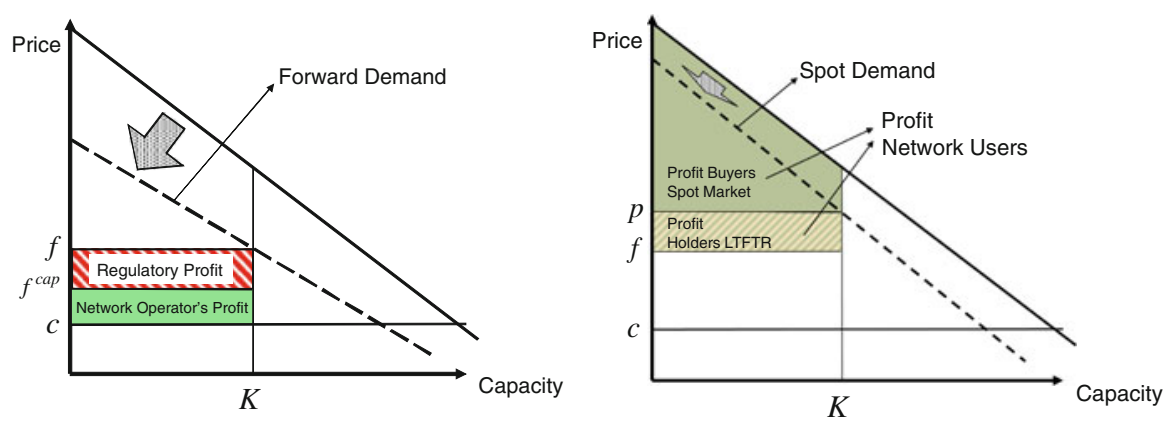

Fig. 3 Forward auctioning (FA). Forward market (left) and spot market (right)

The LTFTR which are auctioned are forward contracts which pay the network user who obtains them the spot price of one product unit in each period of the current block, regardless whether or not that user actually obtains units of the product in the spot market. The forward auction is a uniform price auction with lowest-accepted-bid pricing. All network users pay the same per-unit, per-period market price $f$ and there is a price-cap of $f^{\text {cap }} \mathrm{ECU}$ in place.

The network operator must offer to sell every unit of the product it has in the forward auction. It also must offer the maximum number of units of the product that it can provide with its current network capacity in the spot auction. This implies that the operator always uses its entire revenue from the spot auction to compensate the network users who acquired forward contracts. Thus, its profit is determined exclusively in the forward market. ${ }^{19}$ The spot market is effectively a secondary market.

The operator's profit is shown in Fig. 3. In the figure on the left, the revealed demand in the forward auction is indicated in the dashed line labeled "Forward Demand". The profit to the network operator is given by $\left(f^{c a p}-c\right) \cdot K$, and regulator payoff is equal to $\left(f-f^{c a p}\right) \cdot K$. The figure on the right presents the spot market. The revealed demand in the spot market is illustrated with the dashed line labeled "Spot Demand". The surplus of the buyers in the spot market is given by the darker area. The auction revenue given by $p \cdot K$ is transferred from buyers in the spot market to holders of LTFTR, and thus $(p-f) \cdot K$ indicates the profit accruing to holders of LTFTR. The sum of both areas is the total profit of network users.

The differences in the timing of activity between treatments are illustrated in Tables 2 and 3. The columns indicate the period within the six-period block, and the rows list the activities that take place. An $\mathrm{X}$ indicates that the activity occurs within the applicable period.

\footnotetext{
19 The network operator must offer all capacity in the forward market. This is a feature of actual markets in the field. For instance, FERC only allows investments in gas pipelines if "...the shippers [are] willing to purchase capacity at a rate that pays the full costs of the project,..." (Carr 2005). In the PJM electricity market, FTR's are offered to bidders as long as the associated flows are technically feasible. For this the network operator conducts the "simultaneous feasibility test" (PJM 2009).
} 
Table 2 Timing of activity in the baseline (B) and regulatory holiday (RH) treatments

\begin{tabular}{|c|c|c|c|c|c|c|}
\hline & \multicolumn{6}{|c|}{ Period within six period block } \\
\hline & 1 & 2 & 3 & 4 & 5 & 6 \\
\hline Users learn their individual valuations for periods $1-6$ & $\mathrm{X}$ & & & & & \\
\hline $\begin{array}{l}\text { Users decide whether to raise their highest two } \\
\text { valuations at a cost }\end{array}$ & $\mathrm{X}$ & & & & & \\
\hline $\begin{array}{l}\text { Operator decides whether to install additional } \\
\text { network capacity }\end{array}$ & $\mathrm{X}$ & & & $\mathrm{X}$ & & \\
\hline Spot Auction & $\mathrm{X}$ & $\mathrm{X}$ & $\mathrm{X}$ & $\mathrm{X}$ & $\mathrm{X}$ & $\mathrm{X}$ \\
\hline
\end{tabular}

Table 3 Timing of activity in the forward auctioning (FA) treatment

\begin{tabular}{|c|c|c|c|c|c|c|}
\hline & \multicolumn{6}{|c|}{ Period within six period block } \\
\hline & 1 & 2 & 3 & 4 & 5 & 6 \\
\hline Users learn their individual valuations for periods $1-6$ & $\mathrm{X}$ & & & & & \\
\hline Network users bid for LTFTR capacity & $\mathrm{X}$ & & & & & \\
\hline $\begin{array}{l}\text { Operator builds additional network capacity, sells all capacity } \\
\text { in LTFTR }\end{array}$ & $\mathrm{X}$ & & & $\mathrm{X}$ & & \\
\hline $\begin{array}{l}\text { Users decide whether to raise their highest two valuations } \\
\text { at a cost }\end{array}$ & $\mathrm{X}$ & & & & & \\
\hline Spot auction & $\mathrm{X}$ & $\mathrm{X}$ & $\mathrm{X}$ & $\mathrm{X}$ & $\mathrm{X}$ & $\mathrm{X}$ \\
\hline
\end{tabular}

\section{Benchmarks}

We use three benchmarks against which to compare the performance of the regulatory mechanisms we consider. The first benchmark is the outcome of the decisions of a benevolent social planner with perfect foresight and facing no regulation, where users pay the competitive equilibrium spot price. The social planner maximizes the sum of user surplus, network operator profit, and government revenue over the 30-period horizon. We also use this theoretical benchmark as a denominator to calculate the efficiency levels of all treatments. The efficiency level provides a measure of the extent to which the maximum possible gains from exchange are realized. The second and third benchmarks correspond to the behavior of a profit maximizing monopolist with perfect foresight, facing the regulatory regimes we implement in the experiment: (1) price cap regulation, and (2) a regulatory holiday for new capacity. We assume that all four network users committed to the largest possible demand increase in each period. We use the price cap regulation benchmark to compare prices and investment levels for both the B and FA treatments.

Figure 4 summarizes the results of the three benchmark simulations, as well as the case of an unregulated monopoly. The total shaded area is the overall market surplus generated. The differently-colored shadings distinguish the network operator's profit, the network users' surplus and, in cases where the market is regulated, the revenue for the government. Price cap regulation generates a total surplus that is close to 


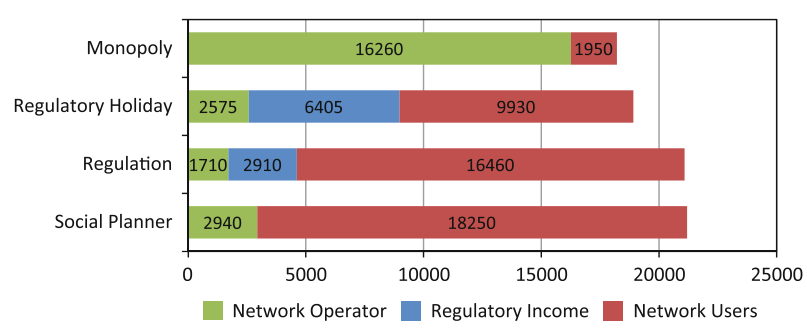

Fig. 4 Operator profit, user surplus, and government revenue

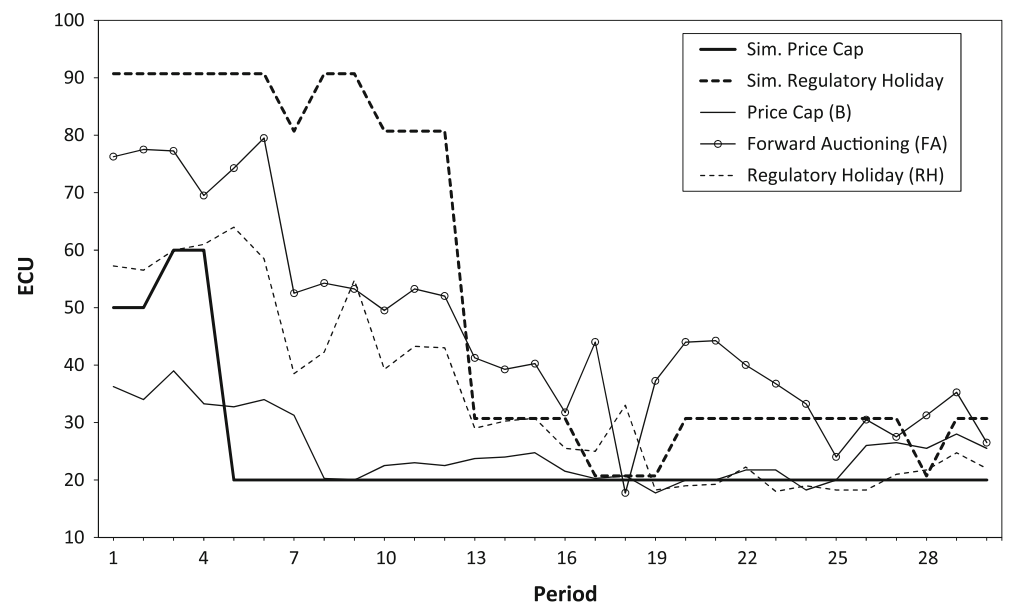

Fig. 5 Spot prices over time: treatment averages

the social planner level. However, the surplus of the network operator is lower under the price cap than under the social planner's policy. The reason for this is that under the social planner's policy, the network operator can earn prices which are as high as 20 in periods with relatively scarce supply, while prices are capped at 15 under price cap regulation. The total surplus under the regulatory holiday is considerably lower, as the amount of investment remains low, and hence prices remain high. The government benefits from the regulatory holiday, as it can collect a large amount of revenue from the units that are subject to a price cap. The network operator also earns more revenue under the regulatory holiday than under the price cap regulation, since it obtains monopoly rents on newly built capacity.

\section{Results}

\subsection{Prices and capacity}

Figure 5 depicts the time series of spot prices for each of the three treatments. Each line presents the average over the four sessions comprising the treatment. The figure also presents the simulation results for the price cap and the regulatory holiday. The simulated outcomes for FA are identical to the B treatment. 
Table 4 Prices, capacity, and efficiency, as a function of treatment

\begin{tabular}{|c|c|c|c|c|c|}
\hline \multirow{2}{*}{$\begin{array}{l}\text { Independent } \\
\text { variable }\end{array}$} & \multicolumn{5}{|c|}{ Dependent variable } \\
\hline & $\begin{array}{l}\text { Price - social } \\
\text { planner price }\end{array}$ & $\begin{array}{l}\text { Capacity - } \\
\text { Soc. Plr. } \\
\text { capacity }\end{array}$ & $\begin{array}{l}\text { Total } \\
\text { efficiency }\end{array}$ & $\begin{array}{l}\text { Allocative } \\
\text { efficiency }\end{array}$ & $\begin{array}{l}\text { Dynamic } \\
\text { efficiency }\end{array}$ \\
\hline Constant & $5.83 *(3.24)$ & $-2.68 * * *(0.56)$ & $0.90 * * *(0.02)$ & $0.97 * * *(0.02)$ & $0.92 * * *(0.02)$ \\
\hline RH tmt. & $9.29 * *(4.30)$ & $-0.18(1.03)$ & $-0.05(0.03)$ & $0.00(0.01)$ & $-0.05(0.03)$ \\
\hline FA tmt. & $21.30 * * *(7.13)$ & $-0.48(0.79)$ & $-0.06(0.03)$ & $-0.03 * * *(0.00)$ & $-0.04(0.03)$ \\
\hline $\mathrm{N}$ (obs.) & 360 & 360 & 360 & 359 & 359 \\
\hline $\mathrm{R} 2$ & 0.16 & 0.01 & 0.05 & 0.06 & 0.05 \\
\hline Prob > Chi2 & 0.01 & 0.83 & 0.06 & 0.00 & 0.20 \\
\hline
\end{tabular}

Prices in the Baseline treatment are very close to those in the corresponding price cap simulations, especially from period 8 onward. This suggests that network operators are behaving close to optimally in the Baseline treatment, and that the cognitive demands of the experiment are within the capabilities of our subjects. Prices in the other two treatments are generally greater than under the Baseline.

The impressions of Fig. 5 are supported by statistical tests. Using a random effects regression of prices on a constant and two treatment dummy-variables, we find that spot prices in the FA and the RH treatments are significantly greater than in the Baseline treatment. This can be seen in the first column of Table 4. In the table RH-tmt and FA-tmt are dummy variables that equal 1 if the observation is from the RH and FA treatments, respectively, and zero otherwise. The dependent variable is the observed price minus the simulated price under the social planner's policy. Error terms are assumed to be clustered at the session level (see Fréchette 2007). In the Baseline treatment, spot prices are 5.8 ECU (experimental currency units) greater than in the social optimum. Prices in the RH and the FA treatments are, respectively, 9.3 and 21.3 ECU greater than in the Baseline. ${ }^{20}$

In the forward auction treatment there are two current prices at any time, the spot price and the forward price of the last auction for LTFTR. Figure 6 shows how the two prices compare on average. It indicates that the spot price is generally considerably greater, by an average of 14.43 ECU. The forward price fails to give an unbiased estimate of the future spot price. Arbitrage between the forward market and the spot market does not succeed in eliminating the price gap.

Figure 7 shows the average capacity over time in each of the three treatments, and in the two benchmark simulations. The price cap simulation has a steadily increasing capacity over the 30 periods, with an interval of constant capacity that corresponds to

\footnotetext{
20 In addition to parametric regressions, we also conduct non-parametric Mann Whitney tests for treatment differences, in which the conservative assumption that each session is one unit of observation is made. These fully concur with the results of the regression analysis with regard to treatment differences. In the rest of this section, we report the results of the random effects regressions; the results of the non-parametric tests can be found in Appendix B.
} 


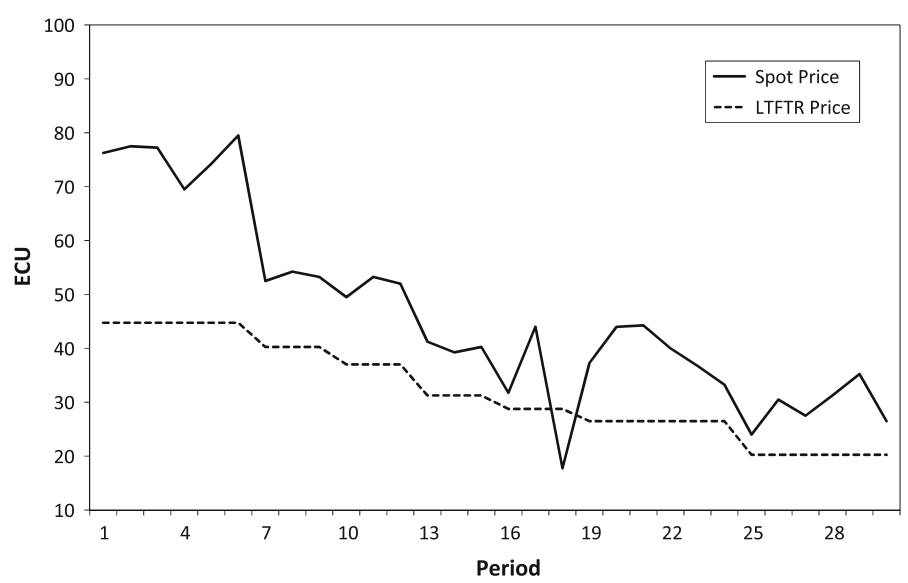

Fig. 6 Spot price and LTFTR price in the forward treatment: averages over all sessions

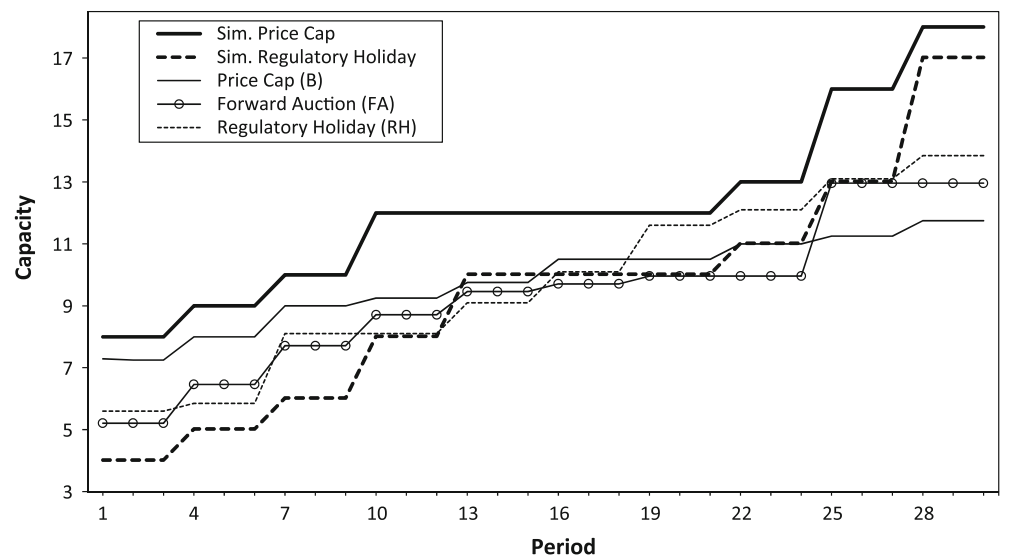

Fig. 7 Installed capacity, treatment averages

a decrease in demand that occurs from periods 14 to 18 . Under the regulatory holiday, the monopolist keeps the initial investment levels low, in order to obtain the monopoly profit over a long interval of periods.

In the Baseline treatment the amount of installed capacity falls consistently short of the price cap benchmark. It does, however, exceed the levels in the other two treatments in the early periods, thereafter falling behind in the late periods. The pace of capacity expansion seems to be largely unaffected by the temporary drop in demand in $\mathrm{RH}$, while in the other two treatments investment recovers more slowly. The second column of data in Table 4 reports regressions of the shortfall of investment on a constant term and the treatment dummies. The shortfall is defined as the actual installed capacity minus the socially optimal quantity. There are no significant treatment effects, but the amount of available capacity in all treatments is lower than socially optimal. 


\subsection{Demand for capacity}

There is substantial underbidding in the spot market in the B and RH treatments, as well as in the forward market in FA. There is also more variability in demand in FA than in the other two treatments. Full demand revelation occurs on average only in the spot market in FA, but is nevertheless characterized by a mix of over- and underbidding. The low spot prices in B and RH appear to induce a belief on the part of the network operator that spot demand is weak. In FA, the fact that forward prices are variable, as well as lower than spot prices, may induce a belief that future demand is volatile and likely to decline. These inferences would have a negative effect on investment in all treatments.

To analyze bidding behavior, we distinguish between (a) revealed demand, the demand function equivalent to the array of bids that users submit, and (b) underlying demand, corresponding to their induced willingness to pay. We construct a smoothed normalized market revealed demand function. In order to compute this function, we first array all of the bids of the users from highest to lowest to obtain a market revealed demand function. The market revealed demand function is then normalized, by dividing it by the underlying demand, evaluated at the price cap. This normalization corrects for changes in demand over time. We then use a LOESS kernel regression (Cleveland 1979) to smooth the normalized functions over the 30 periods and 4 sessions that make up each treatment. Each smoothed revealed demand function summarizes information from 2880 price-quantity vectors. $^{21}$

Figure 8 shows the revealed demand in the market. Each dot corresponds to the normalized revealed quantity demanded, evaluated at a given price for a group in a given period. Thus, for each group in each period, there is one dot for each quantity step in the inverse aggregate revealed demand function. Lines in each panel of the figure show the smoothed normalized revealed demand function and its $60 \%$ confidence intervals for the spot market of the B, FA and RH treatments, and for the forward market of the FA treatment. The figure also presents the underlying demand function, using the same technique for normalization.

In the spot markets under B and $\mathrm{RH}$, and in the forward market under FA, it appears that strategic underbidding is the primary source of the underrevelation of demand evident in the figure. Comparison of the error bounds shows that demand uncertainty, from the point of view of the network operator, is greater in the forward market under Forward Auction. This may be due to the complexity of formulating a bid in the forward market, where users have to aggregate their own demand function for several future periods, and take into account expectations about future spot prices. This would lead to more heterogeneous revealed demand functions, as different bidders solve this bid formulation problem differently.

In the FA spot markets, users who are hedged with LTFTR and who do wish to purchase the corresponding units have no incentive to underbid and reduced cost from overbidding, since they are rebated the market price for these units. This tends to offset the strategic underbidding of other agents, and allows prices in the spot market to

$\overline{214 \text { treatments } * 30 \text { time periods }} * 24$ price quantity vectors (one for each possible quantity demanded). 
roughly correspond to underlying demand on average. However, as a consequence the revealed demand function in the spot market is not only less elastic than the revealed demand function in the forward market, but also less elastic than underlying demand.

\subsection{Efficiency}

We now compare the treatments in terms of the total surplus they generate and how it is divided among the stakeholders. We define Total Efficiency $\eta_{t}^{T o t}$ in period $t$ as
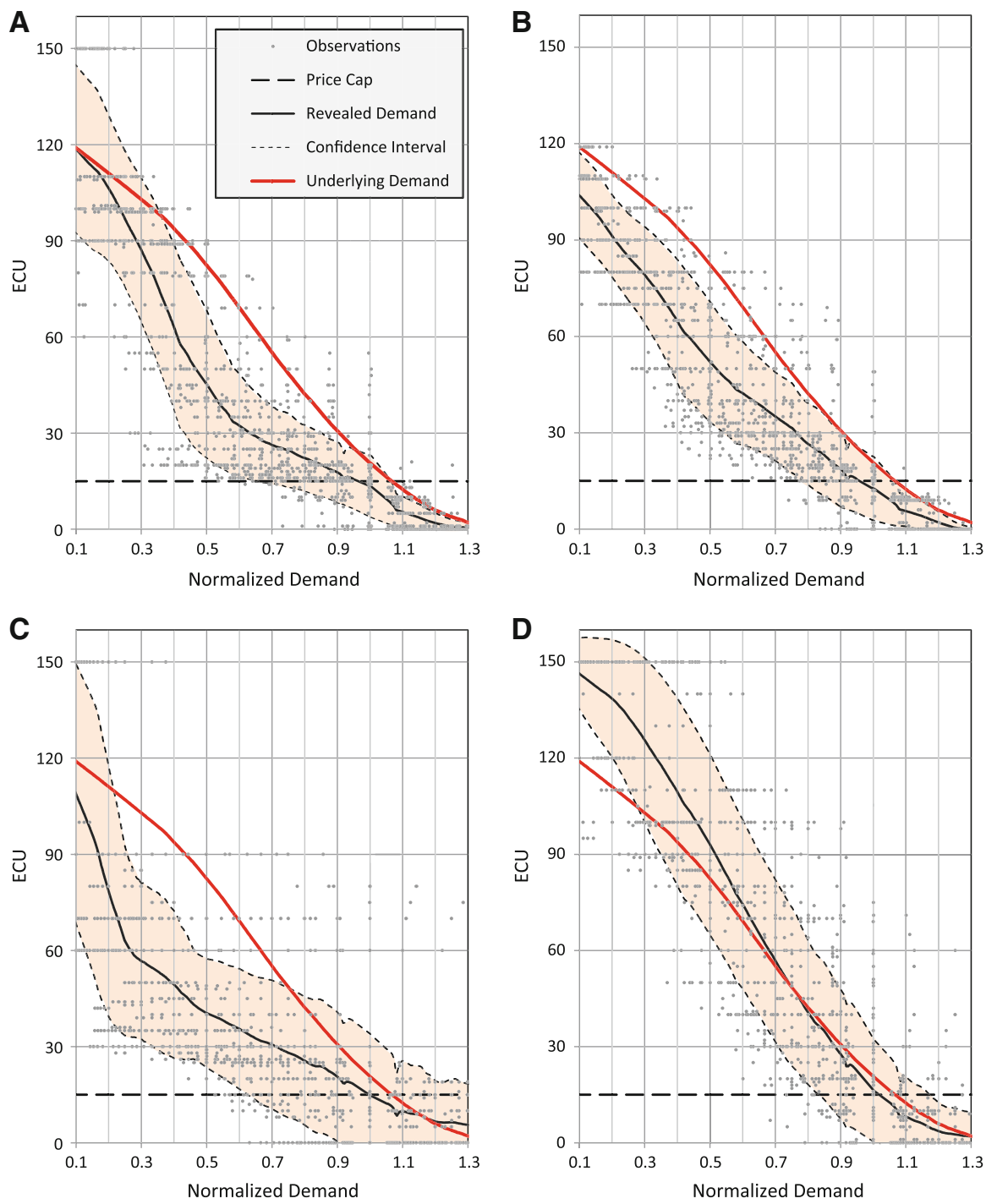

Fig. 8 Smoothed normalized market: revealed and underlying demand. a Baseline, b regulatory holiday, $\mathbf{c}$ forward auctioning, forward market, $\mathbf{d}$ forward auctioning, spot market 
Table 5 Observed and simulated efficiency, all treatments

\begin{tabular}{llllll}
\hline & 1 & 2 & 3 & 4 & 5 \\
& $\begin{array}{l}\text { Total } \\
\text { efficiency } \\
(\%)\end{array}$ & $\begin{array}{l}\text { Static } \\
\text { Efficiency } \\
(\%)\end{array}$ & $\begin{array}{l}\text { Dynamic } \\
\text { efficiency } \\
(1) /(2)(\%)\end{array}$ & $\begin{array}{l}\text { Simulated } \\
\text { dynamic } \\
\text { efficiency } \\
(\%)\end{array}$ & Differ. (4-3) (\%) \\
\hline Baseline & 89.6 & 97.3 & 92.0 & 99.5 & 7.5 \\
Regulatory holiday & 84.3 & 96.9 & 87.1 & 89.2 & 2.1 \\
Forward auctioning & 83.3 & 94.6 & 88.0 & 99.5 & 11.5 \\
\hline
\end{tabular}

the total welfare realized in each period, $W_{t}$, the sum of consumer surplus, network operator's profit and regulatory revenue, divided by the total welfare generated in the social planner simulation in the same period, $W_{t}^{*}$ :

$$
\eta_{t}^{T o t}=W_{t} / W_{t}^{*}
$$

The first column of Table 5 gives the treatment averages for total efficiency. Observed efficiency is greatest in the Baseline treatment: close to $90 \%$ of the maximum feasible welfare level is realized. The values for the RH and FA treatments are $84 \%$ and $83 \%$, respectively. We decompose total efficiency into two multiplicative components: allocative and dynamic efficiency. Allocative efficiency is a measure of how well the spot market performs in awarding the current capacity to the demanders with the greatest valuations. If the highest-valued users fail to receive the units, allocative inefficiency exists. The allocative efficiency $\eta_{t}^{a}$ in period $t$ is defined as:

$$
\eta_{t}^{a}=W_{t} / W_{t}^{o}\left(K_{t}\right)
$$

where $W_{t}^{o}\left(K_{t}\right)$ is the welfare level resulting from allocating the current capacity $K_{t}$ to the users with the highest valuations.

Dynamic efficiency is a measure of the optimality of the timing and the size of investments. Dynamic efficiency is the fraction of the globally optimal welfare that could be reached with an efficient allocation of the actual current capacity. Dynamic efficiency is defined as:

$$
\eta_{t}^{d}=W_{t}^{o}\left(K_{t}\right) / W_{t}^{*}
$$

The second column of Table 5 reports that allocative efficiency is almost identical in the B and RH treatments (97\%). It is, however, significantly lower in FA (94\%). In the B and RH treatments, although users bid strategically by lowering their bids, the individual ranking of their bids still reflects their ranking of willingness to pay.

The results do not support the contention that the forward market improves allocative efficiency. Rather, they suggest that the allocation in the two-stage market consisting of a forward market followed by a spot market, is less efficient than in a spot market operating alone, as in the Baseline and Regulatory Holiday treatments. The spot market does improve the initial allocation of the forward market. The forward 
Table 6 Distribution of surplus among the three types of agents

\begin{tabular}{lllllll}
\hline & \multicolumn{2}{l}{ Operator's profit } & Users' profit & \multicolumn{2}{l}{ Government revenue } \\
\hline Constant & $44.55^{* * *}$ & 1.69 & $499.65^{* * *}$ & 34.91 & $86.97 * * *$ & 27.28 \\
Holiday & $24.46^{* * *}$ & 4.06 & -69.31 & 51.36 & 15.93 & 32.00 \\
Forward & -0.05 & 4.36 & -80.92 & 79.03 & 44.38 & 66.65 \\
Obs. & 360 & & 360 & & 360 & \\
$\mathrm{R}^{2}$ & 0.22 & & 0.03 & & 0.03 & \\
Prob. $>\chi^{2}$ & 0.00 & & 0.00 & & 0.00 & \\
\hline
\end{tabular}

market allocates the network capacity at an average allocative efficiency of $89 \%$. The spot market improves the allocation by $5 \%$.

The third column of Table 5 indicates that dynamic efficiency is also greatest in the Baseline treatment $(92 \%)$ and somewhat lower in the other two treatments. Dynamic efficiency averages $88 \%$ in the Forward Auction treatment and $87 \%$ in the Regulatory Holiday Treatment. However, as shown in Table 4, none of the differences between treatments is significant.

The fourth column of Table 5 reports the efficiency levels obtained in the corresponding simulations. These yield total efficiencies of $99.5 \%, 89.2 \%$ and $99.5 \%$ for the Baseline, the Regulatory Holiday, and the Forward Auction treatment, respectively. The fifth column compares the dynamic efficiency of the simulations and the experimental results. The inefficiency in the RH treatment is anticipated in the simulation results and is consistent with strategic underinvestment on the part of the network operator to exploit market power. However, in the FA treatment, the efficiency level is considerably lower than in the simulation, due to lower investment.

The division of payoffs among the three type of stakeholder, network operator, user, and regulatory authority, differs by treatment. Table 6 reports the results of a regression analysis, in which a constant and treatment dummies are the independent variables and the profits of each type of agent are the dependent variables. In the Baseline treatment, the bulk of the surplus is in the form of consumer surplus. Under the regulatory holiday, government revenue decreases, as it taxes fewer units than under the other policies. Consumer surplus declines and network operator profit increases relative to the other policies, since the network operator is free to charge high prices, and there are fewer units of capacity available. Under the forward auction, there are no significant differences from the Baseline treatment. The high spot prices in FA do induce an insignificant increase in government revenue and reduction in consumer surplus.

\section{Conclusion}

In this paper, we have used an experimental approach to evaluate two policies that have been proposed to induce an operator of a network to increase capacity along an efficient time trajectory. The baseline that we use is an industry with a cap on fees for use of its capacity. This is the typical status of network operators in the European 
gas, electric, and telecommunications industries. ${ }^{22}$ Our price cap is set at a level at which an optimizing network operator would operate at close to the social optimum if demanders behaved as naïve price takers, and the operators could fully anticipate all shocks to demand. However, the environment is complex, users have some market power, and there is no way for a firm to anticipate the unpredictable changes in demand, so that some inefficiency might be expected. Indeed in the Baseline treatment, the realized surplus is roughly $10 \%$ below the optimal level. In the Baseline, as in the other two treatments, less than one half of the inefficiency is due to misallocation of existing capacity. This indicates that the uniform price auction performs well at allocating units to users with the highest valuations and most inefficiency is a result of suboptimal capacity investment.

We find that a regulatory holiday fails to close this gap and, on the contrary, causes it to widen. This is predicted by the simulation analysis that we have conducted that assumes an optimizing monopolist. The removal of a price cap on marginal units causes the firm to slow capacity expansion relative to the Baseline treatment, reducing the quantity of access units supplied to the market closer to the monopoly level. This behavior serves to increase prices and shift rent away from consumers and to the firm. Efficiency losses are mainly due to suboptimally low investment in capacity, and are reflected in dynamic inefficiencies. In principle, a regulatory holiday enhances incentives to invest (Gans and King 2003, 2004) and can positively affect market competition in an oligopoly or a competitive market. However, in our monopoly setting, the regulatory holiday also encourages the exercise of market power.

Forward auctioning also generates lower surplus than the price cap. These inefficiencies were unanticipated from our simulations. Capacity expansion is slower and prices are higher than under the price cap alone, as well as in comparison to the simulation. Spot prices are closer to underlying demand than in the Baseline and the Regulatory Holiday treatments. Forward auctioning improves price discovery in the spot market. However, strategic bidding behavior reduces allocative efficiency by severing the close link between bids and underlying valuations. Forward prices in the Forward Auction treatment are more volatile than spot prices in the Baseline and the Regulatory Holiday treatment. This may lead the network operator in FA to believe that future demand is volatile and reduce investment incentives. This reduces dynamic efficiency. In principle, by selling LTFTRs, the network operator locks-in the price of transmission capacity for several periods and can reduce its revenue uncertainty. However, in our experiment, the effect of increased volatility appears to outweigh that of additional hedging opportunities.

Although the Forward Auction treatment did not perform as well as the Baseline, the opposite might be the case under different market conditions. For example, as uncertainty about demand growth increases, the network operator might find it harder to determine the optimal level of investments in the Baseline treatment and the addi-

\footnotetext{
22 One interesting additional treatment would be to look at a different Baseline environment with no price cap regulation. This would allow the network operator to extract monopoly rents over his entire capacity. Operator behavior in the regulatory holiday treatment suggests that an unregulated monopolist would be Footnote 22 continued able to readily withhold new investment and raise prices to well above competitive levels. This would likely result in low dynamic efficiency.
} 
tional information LTFTRs provide might lead to better investment decisions. Furthermore, improvements to the design of the LTFTR auctions might enhance allocative efficiency. For example, increasing the contract duration of LTFTRs would reduce the risk for the network operators and mitigate the downside of increased volatility.

Another feature of our design is that the regulatory authority is passive. This facilitates a focus on the economic effects of the regulatory policies themselves, since they are applied exogenously and are fixed for the duration of the life of the economy. An interesting agenda for follow-up work would be to assign experimental participants as regulators, and give them discretion over regulatory policy. This would allow them to test different policies and then to settle on ones they believe are working well. It would also permit the investigation of network operators' and users' reaction to policy uncertainty. Different treatments could investigate the effect of varying the regulator's objective function, available set of policies, and commitment power.

Regulatory holidays and LTFTR are institutional features that have been proposed to increase capacity investment by a regulated monopoly. They are supported by solid economic intuition that they would perform well. However, such intuition relies on specific assumptions about how agents interpret and use institutions, and these assumptions may or may not be satisfied. The two systems were not successful, and indeed were counterproductive, in our setting. In particular, the data highlight the strategic behavior of network users in influencing the efficiency of the different regulatory schemes. Underrevelation of demand, present in all of the treatments, may lead the network operator to optimize for a level of demand considerably lower than the true level. Strategic behavior in the Forward Auction treatment reduced allocative efficiency and increased volatility, leading to lower investment levels. In our view, our results constitute an example of the value of laboratory experimental tests of new policies before they are applied in the field.

Acknowledgements The authors thank two anonymous referees, Christoph Engel, Machiel Mulder, Jo Van Biesebroeck, Christian von Hirschhausen, David Newbery, Stef Proost, Juan Rosselón and Ingo Vogelsang, as well as seminar participants at Tilburg University, Groningen University, the Research Institute of Industrial Economics Stockholm, K.U. Leuven, the 2009 International ESA Conference in Washington DC, the Toulouse Energy Conference 2009, the 2009 Infraday Conference in Berlin, the 2010 CLEEN workshop in Amsterdam, the 2011 IAEE conference in Stockholm, the 2011 ESA Conference in Luxemburg, the 2011 CRNI Conference in Brussels for their comments. The authors are responsible for any remaining mistakes. Bert Willems was the recipient of a Marie Curie Intra European Fellowship (PIEF-GA-2008-221085). He thanks the Electricity Policy Group at Cambridge University for their hospitality. Funding by the NMa and CentER for conducting the experiments is gratefully acknowledged. This paper builds upon TILEC report 2010-01, a project conducted in collaboration with the ERGEG's Gas Regulators Initiative North-Western Europe (GRI NW).

Open Access This article is distributed under the terms of the Creative Commons Attribution License which permits any use, distribution, and reproduction in any medium, provided the original author(s) and the source are credited.

\section{Appendix A: Demand valuations}

See Figs. A-1 and A-2. 


\begin{tabular}{|c|c|c|c|c|c|c|c|c|c|c|c|c|c|c|c|c|c|c|c|c|c|c|}
\hline & 1 & 2 & 3 & 4 & 5 & 6 & 7 & 8 & 9 & 10 & 11 & 12 & 13 & 14 & 15 & 16 & 17 & 18 & 19 & 20 & 21 & 22 \\
\hline eriod 1 & 80 & 70 & 60 & 50 & 40 & 30 & 20 & 10 & 0 & 0 & 0 & 0 & 0 & 0 & 0 & 0 & 0 & 0 & 0 & 0 & 0 & 0 \\
\hline riod 2 & 80 & 70 & 60 & 50 & 4 & 30 & 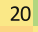 & 10 & 0 & 0 & 0 & 0 & 0 & 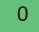 & 0 & 0 & 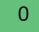 & 0 & & 0 & 0 & \\
\hline 3 & 30 & 70 & 60 & 50 & 4 & 40 & 30 & 20 & 10 & 0 & 0 & 0 & 0 & 0 & 0 & 0 & 0 & 0 & & 0 & 0 & $c$ \\
\hline & 0 & 70 & 60 & 5 & 5 & 40 & 3 & 20 & 10 & 0 & 0 & 0 & 0 & 0 & 0 & & & & & ) & 0 & $c$ \\
\hline & 80 & 70 & 60 & 6 & 5 & 40 & 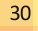 & 2 & 20 & 1 & 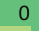 & 0 & 0 & 0 & 0 & 0 & & 0 & & 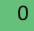 & 0 & $c$ \\
\hline & 80 & 7 & 70 & 6 & 5 & 40 & 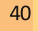 & 30 & 20 & 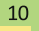 & 10 & 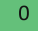 & 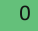 & - & B & 0 & 0 & 0 & & 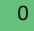 & 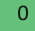 & 0 \\
\hline & 80 & 7 & 70 & 60 & 5 & 40 & 40 & 30 & 20 & 20 & 10 & - & 0 & 0 & 0 & 0 & 0 & 0 & & ) & 0 & 0 \\
\hline & 80 & 7 & 70 & 60 & 5 & 50 & 4 & 35 & 30 & 20 & 1 & 10 & 0 & 0 & 0 & & & 0 & & & 0 & 0 \\
\hline & 80 & 70 & 7 & 60 & 50 & 5 & 4 & 30 & 3 & & 2 & 1 & 0 & 0 & r & 0 & & 0 & & & 0 & 0 \\
\hline & 80 & 7 & 7 & 60 & 60 & 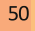 & 40 & 4 & 3 & & 2 & 1 & 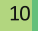 & 0 & 0 & 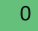 & & 0 & & & 0 & 0 \\
\hline & 80 & 7 & 7 & 60 & 60 & 5 & 4 & 4 & 3 & & 2 & 2 & 10 & 0 & 0 & 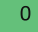 & & 0 & & & 0 & 0 \\
\hline & 80 & 7 & 7 & 60 & 6 & 5 & 5 & 4 & 4 & & 2 & 2 & 10 & 10 & 0 & 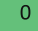 & & 0 & & & 0 & 0 \\
\hline & 0 & 7 & 70 & 60 & 6 & 50 & 50 & 40 & 4 & 30 & 2 & 2 & 10 & 10 & 0 & 0 & & 0 & & & 0 & 0 \\
\hline & 80 & 70 & 70 & 6 & 6 & 50 & 50 & 40 & 40 & 30 & 20 & 20 & 1 & 10 & 0 & 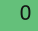 & 0 & 0 & & 0 & 0 & 0 \\
\hline & 80 & 70 & 70 & 6 & 6 & 50 & 5 & 40 & 40 & 3 & 20 & 20 & 10 & 10 & 0 & 0 & 0 & 0 & & 0 & 0 & 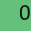 \\
\hline $\mathrm{P}$ & 80 & 70 & 70 & 60 & 6 & 50 & 4 & 40 & 30 & 30 & 20 & 20 & 10 & 0 & 0 & 0 & 0 & 0 & & 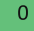 & 0 & $c$ \\
\hline Per & 80 & 70 & 70 & 60 & 60 & 50 & 40 & 40 & 30 & 20 & 20 & 10 & 10 & 0 & 0 & 0 & 0 & 0 & c & 0 & 0 & $c$ \\
\hline Per & 80 & 70 & 70 & 60 & 50 & 50 & 40 & 30 & 30 & 20 & 10 & 10 & 0 & 0 & 0 & 0 & 0 & 0 & 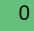 & 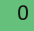 & 0 & $c$ \\
\hline 19 & 80 & 70 & 70 & 60 & 60 & 50 & 40 & 40 & 30 & 20 & 20 & 10 & 10 & 0 & 0 & $c$ & 0 & 0 & & 0 & 0 & $c$ \\
\hline d 20 & 80 & 70 & 70 & 60 & 60 & 50 & 40 & 40 & 30 & 30 & 20 & 20 & 10 & 0 & 0 & $c$ & 0 & 0 & 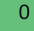 & 0 & 0 & $c$ \\
\hline eriod 21 & 80 & 70 & 70 & 60 & 60 & 50 & 50 & 40 & 40 & 30 & 20 & 20 & 10 & 10 & 0 & $c$ & 0 & 0 & & 0 & 0 & $c$ \\
\hline Period 22 & 80 & 70 & 70 & 60 & 60 & 50 & 50 & 40 & 40 & 30 & 30 & 20 & 20 & 10 & 10 & 0 & 0 & 0 & & 0 & 0 & c \\
\hline Period 23 & 80 & 70 & 70 & 60 & 60 & 50 & 50 & 40 & 40 & 30 & 30 & 20 & 20 & 10 & 10 & 0 & 0 & 0 & c & 0 & 0 & c \\
\hline 2 & 80 & 80 & 70 & 70 & 60 & 60 & 50 & 50 & 40 & 40 & 30 & 30 & 20 & 20 & 10 & 10 & 0 & 0 & ( & 0 & 0 & 0 \\
\hline- & 80 & 80 & 70 & 70 & 60 & 60 & 50 & 50 & 40 & 40 & 30 & 30 & 30 & 20 & 20 & 10 & 10 & 0 & 0 & 0 & 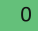 & 0 \\
\hline 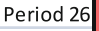 & 80 & 80 & 70 & 70 & 60 & 60 & 50 & 50 & 50 & 40 & 40 & 30 & 30 & 20 & 20 & 20 & 10 & 10 & 0 & 0 & . & . \\
\hline Period 2 & 80 & 80 & 70 & 70 & 60 & 60 & 60 & 50 & 50 & 40 & 40 & 40 & 30 & 30 & 20 & 20 & 10 & 10 & 10 & 0 & . & 0 \\
\hline Peri & 80 & 80 & 70 & 70 & 60 & 60 & 60 & 50 & 50 & 50 & 40 & 40 & 30 & 30 & 30 & 20 & 20 & 10 & 10 & 10 & 0 & 0 \\
\hline 10 & 80 & 80 & 70 & 70 & 7 & 60 & 60 & 50 & 50 & 5 & 40 & 40 & 40 & 30 & 30 & 3 & 20 & 20 & 10 & 10 & 10 & 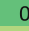 \\
\hline Period 30 & 80 & 80 & 70 & 70 & 70 & 60 & 60 & 60 & 50 & 50 & 50 & 40 & 40 & 40 & 30 & 30 & 30 & 20 & 20 & 10 & 10 & \\
\hline
\end{tabular}

Fig. A-1 Demand valuation of the network users for each period and for each unit (no extra valuation)

\section{Appendix B: Additional regressions}

We replicate the results of regression model reported in Table 4 with a non-parametric Mann Whitney test. The null hypothesis for the two-sided version of the test is that the two treatments come from the same distribution and in the one-sided test that the relationship is opposite in sign to the one in the Table B-1.

\section{Appendix C: Parameter specification}

Our experiment is calibrated to ensure that key variables and ratios take on similar values in the experiment as in the field. The parameters to be chosen consist of those listed in Table 1, as well as the timing of activity and the average and variance of demand growth $g^{t}$.

\section{C.1 Price cap and capacity cost, $p^{c a p}$ and $c$}

The ratio of the price cap $p^{c a p}$ to the capital cost $\mathrm{c},\left(\frac{p^{c a p}}{c}\right)$, links the potential benefits of an investment with the capital cost of new capacity. The ratio is calibrated using information about the capital cost of a typical network operator. 


\begin{tabular}{|c|c|c|c|c|c|c|c|c|c|c|c|c|c|c|c|c|c|c|c|c|c|c|}
\hline & 1 & 2 & 3 & 4 & 5 & 6 & 7 & 8 & 9 & 10 & 11 & 12 & 13 & 14 & 15 & 16 & 17 & 18 & 19 & 20 & 21 & 22 \\
\hline Period 1 & 120 & 110 & 100 & 90 & 80 & 70 & 60 & 50 & 0 & 0 & 0 & 0 & 0 & 0 & 0 & 0 & 0 & 0 & 0 & 0 & 0 & 0 \\
\hline Period 2 & 120 & 110 & 100 & 90 & 80 & 70 & 60 & 50 & 0 & 0 & 0 & 0 & 0 & 0 & 0 & 0 & 0 & 0 & 0 & 0 & 0 & 0 \\
\hline Period 3 & 120 & 110 & 100 & 90 & 80 & 80 & 70 & 60 & 10 & 0 & 0 & 0 & 0 & 0 & 0 & 0 & 0 & 0 & 0 & 0 & 0 & 0 \\
\hline Period 4 & 120 & 110 & 100 & 90 & 90 & 80 & 70 & 60 & 10 & 0 & 0 & 0 & 0 & 0 & 0 & 0 & 0 & 0 & 0 & 0 & 0 & 0 \\
\hline Period 5 & 120 & 110 & 100 & 100 & 90 & 80 & 70 & 60 & 20 & 10 & 0 & 0 & 0 & 0 & 0 & 0 & 0 & 0 & 0 & 0 & 0 & 0 \\
\hline Period 6 & 120 & 110 & 110 & 100 & 90 & 80 & 80 & 70 & 20 & 10 & 10 & 0 & 0 & 0 & 0 & 0 & 0 & 0 & 0 & 0 & 0 & 0 \\
\hline Period 7 & 120 & 110 & 110 & 100 & 90 & 80 & 80 & 70 & 20 & 20 & 10 & 0 & 0 & 0 & 0 & 0 & 0 & 0 & 0 & 0 & 0 & 0 \\
\hline Period 8 & 120 & 110 & 110 & 100 & 90 & 90 & 80 & 70 & 30 & 20 & 10 & 10 & 0 & 0 & 0 & 0 & 0 & 0 & 0 & 0 & 0 & 0 \\
\hline Period 9 & 120 & 110 & 110 & 100 & 90 & 90 & 80 & 70 & 30 & 20 & 20 & 10 & 0 & 0 & 0 & 0 & 0 & 0 & 0 & 0 & 0 & 0 \\
\hline Period 10 & 120 & 110 & 110 & 100 & 100 & 90 & 80 & 80 & 30 & 20 & 20 & 10 & 10 & 0 & 0 & 0 & 0 & 0 & 0 & 0 & 0 & 0 \\
\hline Period 11 & 120 & 110 & 110 & 100 & 100 & 90 & 80 & 80 & 30 & 30 & 20 & 20 & 10 & 0 & 0 & 0 & 0 & 0 & 0 & 0 & 0 & 0 \\
\hline Period 12 & 120 & 110 & 110 & 100 & 100 & 90 & 90 & 80 & 40 & 30 & 20 & 20 & 10 & 10 & 0 & 0 & 0 & 0 & 0 & 0 & U & 0 \\
\hline Period 13 & 120 & 110 & 110 & 100 & 100 & 90 & 90 & 80 & 40 & 30 & 20 & 20 & 10 & 10 & 0 & 0 & 0 & 0 & 0 & 0 & 0 & 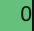 \\
\hline Period 14 & 120 & 110 & 110 & 100 & 100 & 90 & 90 & 80 & 40 & 30 & 20 & 20 & 10 & 10 & 0 & 0 & 0 & 0 & 0 & 0 & 0 & 0 \\
\hline Period 15 & 120 & 110 & 110 & 100 & 100 & 90 & 90 & 80 & 40 & 30 & 20 & 20 & 10 & 10 & 0 & 0 & 0 & 0 & 0 & 0 & 0 & 0 \\
\hline Period 16 & 120 & 110 & 110 & 100 & 100 & 90 & 80 & 80 & 30 & 30 & 20 & 20 & 10 & 0 & 0 & 0 & 0 & 0 & 0 & 0 & 0 & 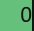 \\
\hline Period 17 & 120 & 110 & 110 & 100 & 100 & 90 & 80 & 80 & 30 & 20 & 20 & 10 & 10 & 0 & 0 & 0 & 0 & 0 & 0 & 0 & 0 & 0 \\
\hline Period 18 & 120 & 110 & 110 & 100 & 90 & 90 & 80 & 70 & 30 & 20 & 10 & 10 & 0 & 0 & 0 & 0 & 0 & 0 & 0 & 0 & 0 & 0 \\
\hline Period 19 & 120 & 110 & 110 & 100 & 100 & 90 & 80 & 80 & 30 & 20 & 20 & 10 & 10 & 0 & 0 & 0 & 0 & 0 & 0 & 0 & 0 & 4 \\
\hline Period 20 & 120 & 110 & 110 & 100 & 100 & 90 & 80 & 80 & 30 & 30 & 20 & 20 & 10 & 0 & 0 & 0 & 0 & 0 & 0 & 0 & 0 & U \\
\hline Period 21 & 120 & 110 & 110 & 100 & 100 & 90 & 90 & 80 & 40 & 30 & 20 & 20 & 10 & 10 & 0 & 0 & 0 & 0 & 0 & 0 & 0 & 0 \\
\hline Period 22 & 120 & 110 & 110 & 100 & 100 & 90 & 90 & 80 & 40 & 30 & 30 & 20 & 20 & 10 & 10 & 0 & 0 & 0 & 0 & 0 & 0 & 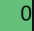 \\
\hline Period 23 & 120 & 110 & 110 & 100 & 100 & 90 & 90 & 80 & 40 & 30 & 30 & 20 & 20 & 10 & 10 & 0 & 0 & 0 & 0 & 0 & 0 & 0 \\
\hline Period 24 & 120 & 110 & 110 & 110 & 100 & 100 & 90 & 90 & 40 & 40 & 30 & 30 & 20 & 20 & 10 & 10 & 0 & 0 & 0 & 0 & U & 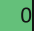 \\
\hline Period 25 & 120 & 110 & 110 & 110 & 100 & 100 & 90 & 90 & 40 & 40 & 30 & 30 & 30 & 20 & 20 & 10 & 10 & 0 & 0 & 0 & 0 & 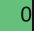 \\
\hline Period 26 & 120 & 110 & 110 & 110 & 100 & 100 & 90 & 90 & 50 & 40 & 40 & 30 & 30 & 20 & 20 & 20 & 10 & 10 & 0 & 0 & 0 & 0 \\
\hline Period 27 & 120 & 110 & 110 & 110 & 100 & 100 & 100 & 90 & 50 & 40 & 40 & 40 & 30 & 30 & 20 & 20 & 10 & 10 & 10 & 0 & 0 & 0 \\
\hline Period 28 & 120 & 110 & 110 & 110 & 100 & 100 & 100 & 90 & 50 & 50 & 40 & 40 & 30 & 30 & 30 & 20 & 20 & 10 & 10 & 10 & 0 & 0 \\
\hline Period 29 & 120 & 110 & 110 & 110 & 110 & 100 & 100 & 90 & 50 & 50 & 40 & 40 & 40 & 30 & 30 & 30 & 20 & 20 & 10 & 10 & 10 & 0 \\
\hline Period 30 & 120 & 110 & 110 & 110 & 110 & 100 & 100 & 100 & 50 & 50 & 50 & 40 & 40 & 40 & 30 & 30 & 30 & 20 & 20 & 10 & 10 & 10 \\
\hline
\end{tabular}

Fig. A-2 Demand valuation of the network users for each period and for each unit (extra valuation)

Table B-1 Mann Whitney tests

\begin{tabular}{|c|c|c|c|c|c|c|c|}
\hline & & \multicolumn{2}{|c|}{ Holiday_price cap } & \multicolumn{2}{|c|}{ Forward-price cap } & \multicolumn{2}{|c|}{ Holiday_price cap } \\
\hline & & 1-sided & 2-sided & 1-sided & 2-sided & 1-sided & 2-sided \\
\hline & Table 4 & & & & & & \\
\hline 1 & $\Delta$ Actual and optimal spot price ${ }^{a}$ & $0.057^{*}$ & 0.114 & $0.014 * *$ & $0.029 * *$ & 0.243 & 0.486 \\
\hline 2 & Actual and optimal capacity & 0.443 & 0.886 & 0.343 & 0.686 & 0.443 & 0.886 \\
\hline 3 & General efficiency & 0.243 & 0.486 & $0.057^{*}$ & 0.114 & 0.557 & 1 \\
\hline 4 & Static efficiency & 0.171 & 0.343 & 0.343 & 0.686 & $0.014 * *$ & $0.029 * *$ \\
\hline 5 & $\begin{array}{l}\text { Dynamic efficiency } \\
\text { Table } 6\end{array}$ & $0.1 *$ & 0.2 & 0.171 & 0.343 & 0.557 & 1 \\
\hline 6 & Network operator's surplus & $0.014 * *$ & $0.029 * *$ & 0.557 & 1 & $0.014 * *$ & $0.029 * *$ \\
\hline 7 & Network users' surplus & 0.171 & 0.343 & 0.243 & 0.486 & 0.443 & 0.886 \\
\hline 8 & Government revenue & 0.443 & 0.886 & 0.557 & 1 & 0.443 & 0.886 \\
\hline
\end{tabular}

Results with two asterisks are significant at the $5 \%$ level, one asterisk at the $10 \%$ level

a The efficient spot price is calculated for the actual invested capacity 

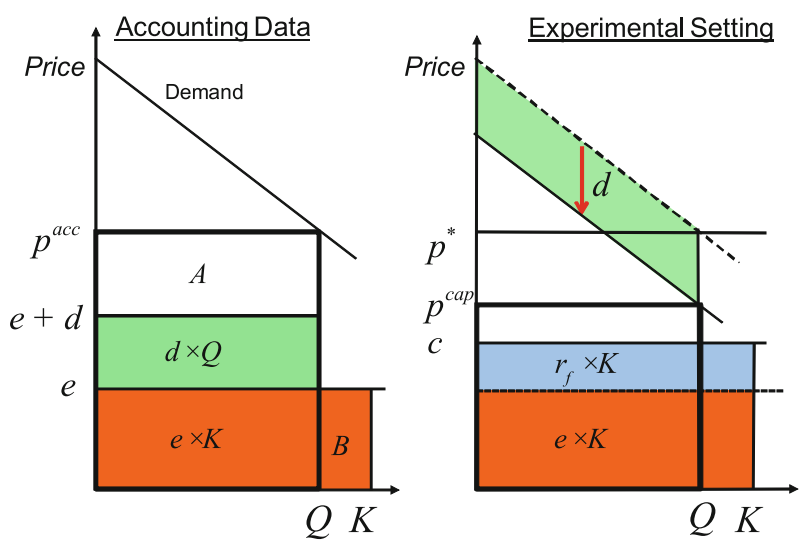

Fig. C-1 Demand, cost and profit of network operator

We assume that the network operator's costs can be divided into two components. Some costs, $e \cdot K$, are proportional to capacity $K$ and are fixed in the short run. Others, $d \cdot Q$, are proportional to quantity supplied and are variable in the short-run. The accounting profit $\pi$ that the firm earns is distributed to shareholders, in a manner proportional to equity and thus to installed capacity, so that $\pi=r \cdot K$. Therefore:

$$
\pi=r \cdot K=p^{a c c} \cdot Q+e \cdot K+d \cdot Q
$$

with $p^{a c c}$ the accounting price. These values are illustrated in Fig. C-1. $d \cdot Q$ is given in green (light shading), $c \cdot K$ in orange (dark shading), and $r \cdot K$ is equal to the area $\mathrm{A}$ minus B. Actual investment behavior is however not driven by accounting profit, but by economic profit, which is equal to accounting profit minus the opportunity cost of capital. The latter cost is assumed to be proportional to the risk free-rate, $r_{f} \cdot K$ and reflects the fact there are alternative uses for capital. Alternative investment options are not part of the experiment, and the opportunity cost of capital therefore needs to be reflected in the capital cost parameter $c$ (Fig. C-1).

We use data of the Belgian gas transportation company Fluxis (2010) to calibrate the parameters (Table C-1). We assume that half of the costs, other than payments to shareholders and bondholders, are capacity related, and the other half are transportation related. The relative size of the payments to shareholders and the bondholders depends on the respective interest rates and the capital structure of the firm. Fluxis has a weighted average cost of capital (WACC) of 6.6\%. Its return on equity (ROE) is about $10 \%$, bondholders receive about $4 \%$ interest, and the firm has a debt to capital ratio of $40 \%$. Those numbers are very similar to other utilities, and thus it is not an atypical network operator. ${ }^{23}$ We assume a risk free rate of $2 \%$. Thus, the opportunity cost of capital $\left(r_{f} \cdot K\right)$ is approximately one fifth of the total payment to shareholders.

23 Oxera (2011) reports WACCs for European network operators ranging from $6.01 \%$ to $6.51 \%$, and estimates the ROE of the Dutch gas network operator GTS in the range of [6.5, 9.8\%]. Macolm and Olsen (2011) observe an average ROE of $17 \%$ for pipelines in the U.S. 
Table C-1 Allocation of revenue of Fluxis and interpretation in our experiment

\begin{tabular}{|c|c|c|c|}
\hline & \multirow[t]{2}{*}{ How is revenue spent? ${ }^{\mathrm{a}}$} & \multicolumn{2}{|l|}{ Assumptions } \\
\hline & & $\begin{array}{l}\text { Proportional to } \\
\text { investment } K\end{array}$ & $\begin{array}{l}\text { Proportional to } \\
\text { transportation } Q\end{array}$ \\
\hline Revenue & 100 & & $100\left(p^{a c c} Q\right)$ \\
\hline $\begin{array}{l}\text { Payments to shareholders } \\
\text { (10\% of equity) }\end{array}$ & 26 & $26(r K)$ & 0 \\
\hline $\begin{array}{l}\text { Payments to bondholders } \\
\text { ( } 4 \% \text { of debt) }\end{array}$ & 15 & 15 component of $(e K)$ & 0 \\
\hline Other costs ${ }^{b}$ & 59 & 29.5 component of $(e K)$ & $29.5(d K)$ \\
\hline $\begin{array}{l}\text { Opportunity cost of } \\
\text { capital }^{\mathrm{c}}(2 \% \text { of equity) }\end{array}$ & - & $5.2\left(r_{f} K\right)$ & \\
\hline
\end{tabular}

There are no variable $\operatorname{costs} d \cdot Q$ in our experiment. We wish to construct similar ratios of net revenue to total capital costs in our experiment as those given in Table C-1, namely

$$
\frac{p^{c a p} \cdot Q}{c \cdot K}=\frac{\left(p^{a c c}-d\right) Q}{\left(r_{f}+e\right) K}=\frac{100-29.5}{5.2+15+29.5}=\frac{70.5}{49.7}=142 \%
$$

To achieve this, $p^{c a p} / c$ would be set at 1.42 if $K=Q$. However, in our environment, we could expect $K$ to modestly exceed $Q$ on average because of temporary overinvestment or low demand, and thus the actual realized ratio of $p^{c a p} / c$ to be lower than the level specified under the assumption that $K=Q$. Hence we set the ratio equal to 1.5 in the event that $K=Q$. Setting $c$ arbitrarily at 10 , we thus obtain $p^{c a p}=15$.

\section{C.2 Equilibrium price and Demand Elasticity, $p^{*}, a$, and $b$}

The demand function was chosen in an attempt to attain an elasticity of demand, $\varepsilon=\frac{d q}{d p} \frac{p}{q}$, close to estimates of the demand function for natural gas. Using time series data from 1973 till 1999, Krichene (2002) finds short-run demand elasticities for natural gas of -0.1 , and long-run elasticities of -1.1 . We use this range of estimates to calibrate the demand function in our experimental environment, and specify equilibrium demand elasticities to be between the short-run and long-run estimates.

In the experiment the variable costs of transportation $d \cdot Q$ are zero. This is not the case in practice. In order to compute demand elasticities that are comparable with the field, we add the variable cost to the experimental price to obtain a comparable 
consumer buyer price $p^{*}$, and calculate demand elasticities at that new price level, while keeping the level of output and the demand slope constant. At the price cap $p^{c a p}=15$, the comparable price level is found by equalizing the following ratios of the experiment and those given in Table C-1:

$$
\frac{p^{*}}{p^{c a p}}=\frac{p^{a c c} \cdot Q}{\left(p^{a c c}-d\right) \cdot Q}=\frac{100}{70.5}=141 \%
$$

This price $p^{*}=15 * 1.41=21.15$, is close to 20 , the predicted buyer price for all periods beginning in period 5 in our simulation of the Benchmark Price Cap treatment. At the price cap $p^{c a p}=15$, and given demand parameter $a=80$, the demand elasticity is -0.31 . Because the intercept with the price-axis $a$ does not change, the demand elasticity at any given price level remains constant over time, even as demand grows. The actual observed market prices, where revealed demand equaled supply, in the experiment were typically between 23 and 38 (this is the price that users pay). In this price range the demand elasticity is greater than at the price cap, and closer to -1 , but smaller than -1 in absolute value. Thus, for the prices observed in our experiment, the demand elasticity is bounded by the short-run and long-run estimates of Krichene (2002) study.

The parameter $b$ is set sufficiently large, so that market demand would not grow too large over the 30 periods; otherwise network users would have to bid for too many units of capacity and the experiment would slow down. On the other hand, $b$ was set sufficiently small so that all network users would have positive quantity demanded in the first period. Thus, demand in the experiment was a discrete approximation of the function $p=80-10\left(q^{t} / g^{t}\right)$.

\section{C.3 Demand growth, $\mathrm{g}^{t}$, time horizon, and demand uncertainty}

To choose the average demand growth for natural gas $E\left[\ln \left(\frac{g_{t}}{g_{t-1}}\right)\right]$ in the experiment, we use the forecasts of world energy outlook of the International Energy Agency (IEA). The IEA (1999) world energy outlook gives an average demand growth of $1.5 \%$ per year in its reference scenario. In our experiment we have a demand growth of $3.5 \%$ per period. Thus, each period in our experiment represents approximately 2.33 years. The time horizon of the experiment is 30 periods, which corresponds to a 70 year time frame. In the field, the useful lifetime of gas pipelines is 50 years for accounting purposes, but if pipelines are well-maintained their lifetime can be extended beyond this period. Thus, an overall life of 70 years is realistic for the type of infrastructure investments that we consider. The forward contracts in the experiment last up to 6 periods, corresponding to 14 years in the field. Von Hirschhausen and Neumann (2008) report that the typical contract duration for bilateral European gas contracts is about 19 years (with a standard deviation of 8 years). However, in practice tradable forward contracts often have a shorter duration.

The uncertainty about the demand growth can be measured as the standard deviation of growth $S T D\left(\ln \left(\frac{g_{t}}{g_{t-1}}\right)\right)$. For this parameter we compare possible outcomes in our model with the range of predictions of the IEA. The IEA 2009 report gives 
three alternative scenarios for demand predictions over the period 2007-2030. The first alternative scenario assumes that future $\mathrm{CO} 2$ concentrations would be limited to $450 \mathrm{ppm}$. The demand growth for gas would then slow to $0.7 \%$ per year. Two other scenarios look at the sensitivity of the growth rate with respect to price dynamics. In a high-and a low-price scenario, demand growth is predicted to be 1.3 and $1.8 \%$ per year, respectively. Hence the IEA reports alternative scenarios with growth rates of $0.7,1.3$ and $1.8 \%$.

After modeling the demand growth in the experiment as a geometric Brownian motion, we calculate the $95 \%$ confidence interval of demand growth over 23 years, which corresponds to 10 periods in the experiment. We set this interval for the experiment to $[0.7 \%, 2.3 \%]$, which is similar to the range of scenarios given by the IEA. The average demand growth per period is $3.5 \%$, with a $95 \%$ confidence-interval of $[-2.1 \%, 9.4 \%]$. Over longer time periods, this confidence interval becomes smaller, as we would have to take the average over some high growth and some low growth periods.

\section{C.4 Choice of other parameters}

The parameter $\triangle K^{M A X}$ is the limit on the amount of investment in capacity the network operator can make every 3 periods. This was intended to reflect that large increases in capacity are technically feasible. Along the optimal investment path, the maximum is not binding. If the network operator invests the maximum $\triangle K^{M A X}=5$ units whenever he could, total capacity would be 54, much larger than total demand, which always remains lower than 22 units.

The initial network capacity $K_{0}$ is set at a level relative to initial demand so that the network operator would make a similar investment in the first period as in all subsequent periods.

The parameters $\gamma$ and $\kappa$ adjust the demand function for the first two units of demand for each network user. These are set to reflect the tradeoff from taking on large commitments to supply powerful downstream users. These require a specific investment, are very profitable if fulfilled, and particularly costly to fail to fulfill. With the parameters we have chosen, network users will only make a loss on these contracts if they do not obtain any network capacity in the market. If they obtain at least 2 units, they make a profit of at least $60 \mathrm{ECU}$.

\section{Appendix D: Instructions}

The following section contains the text of the instructions for the price cap treatment. Additions or replacements made in the instructions for the Holiday- and Forward Auction treatment respectively are indicated as such. 


\section{Welcome!}

Thank you very much for your participation in this experiment! If you follow the instructions carefully and make good decisions, you can earn a considerable amount of money, which will be paid to you in cash at the end of the experiment.

The experiment will be made up of a series of periods. You are either a Type A or a Type B Player. There will be exactly 4 Type A Players and 1 Type B Player in the experiment. You will remain the same type of player in each period.

The money used in the experiment is ECU, or Experimental Currency Units. The ECU that you earn in the experiment will be converted to Euros and paid to you.

In each period, there will be a good sold called X. Type A Players can earn money by buying X, while the Type B Player can earn money by selling X.

Pages ( ) discuss specific information for Type A Players while Pages () discuss specific Information for the Type B Player. Page () provides you with information on the proceedings during the Experiment.

\section{(1) \\ Specific Instructions for Type A Players \\ Type A Players can earn money by buying $\mathrm{X}$ at low prices.}

\section{Buying X:}

In each period you can buy units of a good called X. You will receive ECU for each unit of X that you buy in each period. The amount of ECU that each unit of X that you buy pays to you is shown on your computer screen at the beginning of each period. The $\mathrm{X}$ that you buy only lasts one period, so you need to buy more $\mathrm{X}$ each period to earn money in every period.

(2)

Please consider now Screenshot 1 issued to you separately. Its layout is similar to many screens which a Type A Player will encounter. Each period from $1-6$ is shown in a different column. The first number in each "Period column" is the amount of ECU you receive from the first unit of X that you buy in a period. The second number in each column is the additional amount of ECU that you receive from the second unit that you buy in a period, etc... The amount of ECU you receive for a particular unit of $\mathrm{X}$ is also called "Valuation"

In every period, you will have valuations for six (6) units of X. Note though that if the amount of ECU indicated for a particular unit of X (Your Valuation for that unit) is 0 , then you will not receive any ECU for it. Only you know your own Valuations.

\section{Bonus Values:}

Type A Players may pay some money to increase the ECU that some of the units they buy pay off. If you do so, your decision is in effect for the next six periods. You have three options:

- You can pay a total of $60 \mathrm{ECU}$, which will be charged to you in the form of $10 \mathrm{ECU}$ each period for the next 6 periods, to increase the ECU you receive for the first two units you buy by 20 ECU each. This Option is called Bonus Valuation 1.

- You can pay a total of $120 \mathrm{ECU}$, which will be charged to you in the form of $20 \mathrm{ECU}$ each period for the next 6 periods, to increase the ECU you receive for the first two units you buy by 40 ECU each. This Option is called Bonus Valuation 2.

- You can pay 0 ECU and not change the amount of money you receive for the X you buy. This Option is called Standard Valuation.

The raise in the amount of ECU you receive for the first two units of $\mathrm{X}$ is indicated by "+ 20 " (Bonus Valuation 1) or "+ 40" (Bonus Valuation 2) for your valuations of the first two units. 


\section{The Market for $\mathbf{X}$}

In each period, units of $\mathrm{X}$ are sold to Type A Players in an auction. One auction for $\mathrm{X}$ takes place in each period. To buy units of $X$, you must place bids for them. You must place a bid for all six units for which you have a valuation (i.e. also for those for which your valuation is 0 ), but if you do not want to buy a unit, simply enter a " 0 " in the respective field on the screen.

The outcome of the auction is determined according to the following rules:

- The players who make the highest bids receive the $\mathrm{X}$ being sold.

- For example, suppose that the Type B Player offers 5 units of X in period 1.

- Then, in the auction in period 1 , the players who made the five highest bids receive units, one unit for each of the bids they have among the top five.

- The price that every winning bidder pays equals the lowest of the winning bids.

- In the example above with five units for sale, the lowest winning bi $\mathrm{d}$ is the fifth highest bid.

Consider the following illustration of the previous example. The table below indicates the hypothetical bids of the four Type A Players (named Player 1 through Player 4) for X in period 1:

\begin{tabular}{|c|c|c|c|}
\hline Player 1 & Player 2 & Player 3 & Player 4 \\
\hline 13 & 12 & 9 & 5 \\
\hline 6 & 7 & 4 & 5 \\
\hline 0 & 3 & 4 & 4 \\
\hline 0 & 0 & 0 & 3 \\
\hline 0 & 0 & 0 & 1 \\
\hline 0 & 0 & 0 & 1 \\
\hline
\end{tabular}

- Remember that we assume that there are five units of $\mathrm{X}$ for sale.

- The five highest bids are $13,12,9,7$ and 6 .

- The players who submitted these bids receive one unit of $\mathrm{X}$ for each of these top five bids:
- Player 1 receives 2 units of $X(13,6)$
- Player 2 receives 2 units of $X(12,7)$
- Player 3 receives 1 unit of $X$ (9)
- Player 4 receives no units of $X$

- The price that every winning bidder pays is equal to the lowest of the winning bids. In this example, the lowest winning bid is 6 .

- Player 1 receives 2 units of $\mathrm{X}$ for a price of $6 \mathrm{ECU}$ per unit.

- Player 2 receives 2 units of $X$ for a price of 6 ECU per unit.

- Player 3 receives 1 unit of $X$ for a price of 6 ECU per unit.

- Player 4 receives no units of $\mathrm{X}$

If there are more bids equal to the winning bid, it will be randomly determined by the program who of the players which submitted these bids will receive the unit of $\mathrm{X}$. 
(3)

\section{Your income as a Type A player}

In each period, your income as a type A player is equal to:

(4) The value of $X$ you have purchased

+ bonus values on units you have purchased

- money you spend in the auction for $\mathrm{X}$

- money you spend on bonus values

\section{Timing}

The following table shows the actions you will need to take in every block of 6 periods. In period 1 , you can choose a bonus value and then buy X. In periods $2-6$, you can buy X. There is a cycle of six periods, so that period 7 is the same as period 1 , period 8 the same as period 2 , etc...

(5)

\begin{tabular}{|l|r|r|r|r|r|r|}
\hline & \multicolumn{6}{|l|}{ PERIOD } \\
\hline & 1 & 2 & 3 & 4 & 5 & 6 \\
\hline a. Choose Bonus Value & $\mathrm{x}$ & & & & & \\
\hline b. Buy X & $\mathrm{x}$ & $\mathrm{x}$ & $\mathrm{x}$ & $\mathrm{x}$ & $\mathrm{x}$ & $\mathrm{X}$ \\
\hline
\end{tabular}

On the top left corner of every screen in the game, the program tells you exactly at which point you are. If you again have a look at Screenshot 1, you can see that this particular screen provides you with summary information (about your valuations and your bonus choice) just prior to the auction for $\mathrm{X}$ in Period 1. It reads: Period 1.b: Summary. With this information and the table above you can always find out at which point in the game you are!

\section{(6) Specific Instructions for the Type B Player}

\section{The Type B Player can earn money by selling X.}

\section{Selling X \& Expanding Capacity}

In each period, the Type B Player sells units of X. The maximum amount that she can sell is called her capacity. So if her capacity is equal to " $n$ " units, she can at most offer " $n$ " units of X in the auction for X. In every auction of X, the Type A Players submit their bids before the Type B Player decides on the amount of X that she wants to sell. The Type B Player can offer her entire capacity, that is she sells as many units of $\mathrm{X}$ as she can. The Type B Player is however also free to offer less (but at most 10 units of $\mathrm{X}$ less than capacity is available).

For her capacity, the Type B Player incurs a cost: 10 ECU in every period f or each capacity unit, regardless of whether it is actually used to sell $\mathrm{X}$ or not. 
The Type B Player has the opportunity to increase her capacity in every third period, beginning in period 1 . At each of these instances, she can increase her capacity by at most 5 units. The capacity of X the Type B Player starts with in Period 1 is 4 units of X. Recall once more that for each unit of capacity that she has, she must pay $10 \mathrm{ECU}$ in every period. If she increases her capacity, she can never decrease it in the future, and she must pay the 10 ECU fee every period for each unit of capacity she has until the end of the experiment.

\section{Your income as a Type B Player}

(7)

In each period, your income as a Type B Player is equal to:

The money you receive from selling $\mathrm{X}$

- money you spend on capacity

\section{Timing}

The following table shows the actions you will need to take in every block of 6 periods. In period 1 and period 4, can increase your capacity and sell X. In periods 2, 3, and 5, you sell X. There is a cycle of six periods, so that period 7 is the same as period 1, period 8 the same as period 2 , etc...

\begin{tabular}{|l|r|r|r|r|r|r|}
\hline & \multicolumn{6}{|l|}{ PERIOD } \\
\hline & 1 & 2 & 3 & 4 & 5 & 6 \\
\hline a. Increase Capacity & $\mathrm{x}$ & & & $\mathrm{x}$ & & \\
\hline b. Sell X & $\mathrm{x}$ & $\mathrm{x}$ & $\mathrm{x}$ & $\mathrm{x}$ & $\mathrm{x}$ & $\mathrm{x}$ \\
\hline
\end{tabular}

\section{FURTHER PROCEEDINGS IN THIS SESSION}

After we have read these instructions together, you will have the opportunity to ask questions. Then the experimenter will issue a quiz to check your understanding. Performance in the quiz is judged primarily by the correctness of your answers and secondarily on the speed in which you complete the quiz. The first participant with full points (or the highest amount of points in the quiz) will become the Type B Player. The four next best participants will attain the role as Type A Players. The remaining participants will receive 10 Euros for their participation and are asked to leave.

Then the actual experiment begins. There will be three "runs". The first run consists of 12 periods ( 2 blocks). This run is conducted to familiarize you with the procedures and the screens of the experiment. In the first one or two periods, the experimenter will go through the screens with you together and explain to you what you see on each screen. As this run is intended to familiarize you with the experiment, the decisions you take in these 12 periods do not affect your payment at the end of the experiment.

The second run consists of 30 periods ( 5 blocks). Your performance in this run determines your payment at the end of the experiment.

The third and final run consists of 30 periods as well, and again your performance in this run determines your payment at the end of the experiment. 
The proceedings in all of the three runs are identical.

After each run, the computer will prompt you to enter your first and last name. This is solely for the purpose of paying you after the experiment. At no point will that information be published! Also, after each run the experimenter will come to you and restart the program in order to prepare for the next run.

\section{YOUR PAYMENT}

\section{Payment for Type A Players}

In the second and third run, you will be informed on a screen at the onset of the run how the amount of ECU is converted to Euros. This conversion can differ between the second and the third run, as can your valuations. The sum of your earnings in the second and third run determines your payment. You will receive a loan of $500 \mathrm{ECU}$ in the first period of the game (to cover temporary losses, if any) but that loan will automatically be deducted in the final period of the experiment.

\section{Payment for the Type B Player}

In the second and third run, you will be informed on a screen at the onset of the run how the amount of ECU is converted to Euros. This conversion can differ between the second and the third run. The sum of your earnings in the second and third run determines your payment. You will receive a loan of $500 \mathrm{ECU}$ in the first period of the game (to cover temporary losses, if any) but that loan will automatically be deducted in the final period of the experiment.

In addition, you will receive a lump sum payment of 30 Eurocent for each period in runs 2 and 3.

The following changes are made for the different treatments:

\begin{tabular}{|l|l|}
\hline (1) & $\begin{array}{l}\text { IN FA REPLACED BY } \\
\text { In each period, there will be a good sold called X. In every sixth period, beginning in period 1, } \\
\text { there will be another good sold, called insurance. Type A players can earn money by buying X } \\
\text { and insurance, while the type B player can earn money by offering X and selling insurance for } \\
\text { X. }\end{array}$ \\
\hline (2) & $\begin{array}{l}\text { IN FA REPLACED BY } \\
\text { Type A players can earn money by buying X and by buying insurance at low prices. }\end{array}$ \\
\hline Buying Insurance: \\
$\begin{array}{l}\text { In every sixth period, beginning in period 1, you can submit bids for insurance. This occurs } \\
\text { before you choose your bonus values and before the Market for X in that period. You can bid } \\
\text { for it in an auction with the same rules as the market for X (see the previous section). You can } \\
\text { purchase as many units of insurance as you would like, at most six units though, provided that } \\
\text { your bids are high enough and that there are enough units of insurance for sale. The Type B } \\
\text { Player decides in every third period, beginning in period 1, how much insurance she wants to } \\
\text { sell. You do however only submit bids every sixth period (just before you decide on your bonus } \\
\text { values), and these bids determine how much insurance you will obtain each time the Type B } \\
\text { player offers insurance. }\end{array}$ \\
\hline
\end{tabular}




\begin{tabular}{|c|c|c|c|c|c|c|c|}
\hline & \multicolumn{7}{|c|}{$\begin{array}{l}\text { If you receive a unit of insurance, it lasts until the next time you submit bids for } \\
\text { insurance } \\
\text { - In each period until then, it pays you an amount equal to the price of } X \text { in that period } \\
\text { However, you also pay the auction price for the insurance in every period that it lasts } \\
\text { For example, if you obtain } 2 \text { units of insurance for a price of } 20 \text { ECU in the insurance auction in } \\
\text { period } 1 \text {, then you have to pay } 2 \text { x } 20=40 \text { in periods } 1 \text { - } 3 \text {. If the Type B player decides not to } \\
\text { offer any additional units of insurance in period } 4 \text {, you will pay that amount in periods } 4-6 \text { as } \\
\text { well. } \\
\text { The reason it is called insurance is the following. } \\
\text { (1) Suppose that you do not buy a unit of } X \text { in the auction for } X \text { because the auction price } \\
\text { was too high, but you have insurance. Then, you can still benefit from the high price of } X \text {. This } \\
\text { is because one unit of insurance gives you a payment equal to the price for one unit of } X \text {. That } \\
\text { means that the higher the price of } X \text { is, the higher your insurance payout. } \\
\text { (2) If you buy a unit of } X \text {, you can get a refund equal the price you pay if you have a unit } \\
\text { of insurance. This means that you do not pay anything for the unit of } X \text { you bought. Remember } \\
\text { though that you still have to pay for the insurance you bought. }\end{array}$} \\
\hline (4) & \multicolumn{7}{|c|}{$\begin{array}{l}\text { IN FA REPLACED BY } \\
\begin{array}{l}\text { The value of X you have purchased } \\
+ \text { bonus values on units you have purchased } \\
+ \text { insurance payouts you receive } \\
\text { - money you spend in the auction for } \mathrm{X} \\
\text { - money you spend in the auction for insurance } \\
\text { - money you spend on bonus values }\end{array}\end{array}$} \\
\hline \multirow[t]{7}{*}{ (5) } & \multicolumn{7}{|c|}{$\begin{array}{l}\text { IN FA REPLACED BY } \\
\text { The following table shows the actions you will need to take in every block of } 6 \text { periods. In } \\
\text { period } 1 \text {, you can buy insurance, then choose a bonus value and finally buy X. In periods } 2-6 \text {, } \\
\text { you can buy X. In Period } 4 \mathrm{c} \text {, you might receive additional insurance and the price for insurance } \\
\text { might change if the Type B player decides to issue additional insurance. There is a cycle of six } \\
\text { periods, so that period } 7 \text { is the same as period } 1 \text {, period } 8 \text { the same as period 2, etc... }\end{array}$} \\
\hline & \\
\hline & & 1 & 2 & 3 & & 5 & 6 \\
\hline & a. Buy Insurance & $\mathrm{x}$ & & & & & \\
\hline & b. Choose Bonus Value & $\mathrm{X}$ & & & & & \\
\hline & c. Additional Insurance & & & & & & \\
\hline & d. Buy X & $\mathrm{x}$ & $\mathrm{X}$ & $\mathrm{X}$ & & $\bar{X}$ & $\mathrm{x}$ \\
\hline (6) & \multicolumn{7}{|c|}{$\begin{array}{l}\text { "SPECIFIC INSTRUCTIONS FOR THE TYPE B PLAYER" REPLACED IN FA BY } \\
\text { Specific Instructions for the Type B player } \\
\text { The Type B player can earn money by offering X and selling Insurance for X } \\
\text { In each period, the type B player must offer units of X. All units of X that the Type B Player } \\
\text { can provide are automatically offered in the auction discussed on pages } 2 \text { and } 3 \text { of these } \\
\text { instructions. The total number of units of X can provide is called her capacity. The capacity can } \\
\text { be increased but never decreased. The capacity of X the type B player starts with in Period } 1 \text { is } \\
4 \text { units of X. For each unit of capacity that the Type B player has, she incurs a cost of } 10 \text { ECU } \\
\text { in every period. If she increases her capacity, she can never decrease it in the future, and she } \\
\text { must pay the } 10 \text { ECU in every period for each unit of capacity she has until the end of the } \\
\text { experiment. }\end{array}$} \\
\hline
\end{tabular}


The Type B player can increase her capacity every third period beginning from period 1 by at most 5 units. The Type B player is at the same time obliged to offer an identical number of insurance units to the Type A players. This is done automatically.

This requirement has important implications: Recall from the description of Insurance on page () that one unit of Insurance pays a Type A player exactly the Market price for X. Hence, the money which the Type A players spend on buying $X$ in each period's market for $X$ is not kept by the Type B player but instead entirely used to pay out the Type A players according to their holdings of Insurance. Put differently: The Type B player does not have any direct income from offering $X$ to the Type A players.

However, the Type B player can make profits by selling Insurance for her capacity of X. Recall from above that the Type B player must sell one unit of insurance for every unit of her capacity of X. By increasing her capacity, the Type B player sells more Insurance to the Type A players in the Insurance auctions discussed on page 3.

Recall that the Type A players submit bids for insurance every sixth period, i.e. in the first period of each six period block (that is in periods $1,7,13,19$, and 25). In contrast, the Type B player can increase her capacity (and hence offer additional insurance) every third period, and therefore in the first and fourth period of each six period block. Thus, at both opportunities for the Type B player to invest, the bids submitted by the Type A players in the first period of the current six period block are used.

Important: The maximum amount of ECU for selling one unit of insurance which the Type B player is allowed to keep is limited: In case the price for Insurance the Type A players have to pay in the insurance auction described on pages 3 and 4 turns out to be higher than 15 ECU per unit, the Type B player will only receive the 15 ECU per unit of insurance while the difference between the payments of the Type A players and that amount is kept by the computer. Only if the market price for Insurance is below $15 \mathrm{ECU}$, the type B player will obtain the market price for Insurance. Thus, the Type B player can at most receive 15 ECU for each unit of insurance she sells.

The screen that the Type B Player will see when she has to decide on her capacity and number of insurance units to sell for the next three periods is depicted in Screenshot 2. On the left you see a column of red buttons. By pressing one of these, the Type B Player decides on the number of insurance units she sells. If she presses the button at the top, she does not increase her capacity over the current amount and hence does not sell any additional Insurance as well. If she presses the second button, she sells one additional unit of insurance on top of that, if she presses the third one she sells two additional units of insurance and so on. For every choice the screen provides her with the total number of capacity and insurance units which she would then sell (second column), the price per unit of insurance she would receive until the next opportunity to increase her capacity (third column) and finally the profit which she makes by selling them. The profit shown already considers the costs which the Type B player incurs for each unit of capacity.

Note well: The profit displayed is the amount of ECU you make per period from selling the respective number of insurance units. The profit numbers thus tell you how much ECU you can earn with certainty in each remaining period of the current six period block. 
Example1:

Assume that you are in Period 7, hence the first period of the second six period block. Assume that by adding one additional unit of capacity (and hence one additional unit of insurance) the profit indicated is $40 \mathrm{ECU}$. Thus you will receive $40 \mathrm{ECU}$ until period 12 (the final period of that block), assuming that in Period 10, the second opportunity to expand your capacity / and sell additional insurance in the second block, you decide not to add any additional capacity.

Example 2:

We are in the same situation as above, however you are now in period 10 and decide to add capacity in that period as well. Assume your indicated profit is then 45 ECU. You will then obtain 45 ECU in periods 10,11 and 12.

\section{Your income as a type B player}

In each period, your income as a type B player is equal to:

The money you receive from selling Insurance

- money you spend on capacity

\section{Timing}

The following table shows the actions you will need to take in every block of 6 periods. In period 1 and 4, you decide on your capacity and on the amount of insurance you sell. There is a cycle of six periods, so that period 7 is the same as period 1, period 8 the same as period 2, etc...

\begin{tabular}{|l|c|c|c|c|c|c|}
\hline & \multicolumn{2}{|l|}{ PERIOD } \\
\hline & 1 & 2 & 3 & 4 & 5 & 6 \\
\hline Increase Capacity \& Sell Insurance & $\mathrm{x}$ & & & $\mathrm{x}$ & & \\
\hline
\end{tabular}

(7) ADDITIONAL TEXT IN THE REGULATORY HOLIDAY TREATMENT

You earn money by selling $\mathrm{X}$ to the Type A players. The amount of money you receive in a period from selling $\mathrm{X}$ depends not only on the bids which the Type B players submit and the amount of $\mathrm{X}$ that you offer but also on the expansion of capacity during every six period block (the blocks are illustrated on page 3 and on page 7 and start in periods 1, 7, 13, 19 and 25 respectively)

For all units of $\mathrm{X}$ which you can provide with capacity that was already available during the previous block, you obtain a regulated price. That price is equal to $15 \mathrm{ECU}$ for each unit of $\mathrm{X}$ sold if the market price, that is the price which the Type A players pay (refer to page 2 on how that one is calculated), is equal to or higher than $15 \mathrm{ECU}$. You receive the market price only if it is lower than 15 ECU.

For units of $\mathrm{X}$ which you can only offer because you have increased your capacity during the current six period block, you receive the full market price, even if it is higher than $15 \mathrm{ECU}$. Remember that during each six period block, you can increase your capacity twice: Once in the first period of the six period block and then once more three periods later (Have a look at the table on page 7 for an illustration). Please consider the following example which illustrates how your profit as a Type B player is calculated: 
The screen that the Type B Player will see during the stage of deciding on how much of her capacity to use is depicted in Screenshot 2. By pressing one of the red buttons on the left, she decides on the amount of $\mathrm{X}$ to sell. By pressing the highest button, she sells the maximum possible number of $\mathrm{X}$ (her entire capacity), by pressing the one below she sells one unit less, and so on. For every possible choice, the screen tells her the amount of $\mathrm{X}$ she would sell at the regulated price (which is also provided), the amount of $\mathrm{X}$ she would sell at the market price (which is also provided) and finally her profit (her income) from selling X.

Remember: Regardless of whether the Type B Player offers her entire capacity or less, she will incur the cost of 10 ECU for every unit of her capacity. This cost is included in the calculation of the profit that is shown in the final column in the screen depicted in Screenshot 2.

\section{References}

Abbink, K., Brandts, J., \& McDaniel, T. (2003). Asymmetric demand information in uniform and discriminatory call auctions: An experimental analysis motivated by electricity markets. Journal of Regulatory Economics, 23, 125-144.

Allaz, B., \& Vila, J. L. (1993). Cournot competition, forward markets and efficiency. Journal of Economic Theory, 59, 1-16.

Alsemgeest, P., Noussair, C., \& Olson, M. (1998). Experimental comparisons of auctions under single and multi-unit demand. Economic Inquiry, 36(1), 87-97.

Armstrong, M., \& Sappington, D. (2007). Recent developments in the theory of regulation. Handbook of industrial organization (Vol. 3). Amsterdam: Elsevier.

Averch, H., \& Johnson, L. L. (1962). Behavior of the firm under regulatory constraint. American Economic Review, 52(5), 1052-1069.

Brandts, J., Pezanis-Christou, P., \& Schram, A. (2008). Competition with forward contracts: A laboratory analysis motivated by electricity market design. Economic Journal, 118, 192-214.

Brunekreeft, G., \& Newbery, D. (2005). Should merchant transmission investment be subject to a must-offer provision? Journal of Regulatory Economics, 30(3), 233-260.

Bushnell, J., \& Stoft, S. (1996). Electric grid investment under a contract network regime. Journal of Regulatory Economics, 10, 61-79.

Bushnell, J., \& Stoft, S. (1997). Improving private incentives for electric grid investment. Resource \& Energy Economics, 19(1-2), 85-108.

Cambini, C., \& Rondi, L. (2010). Incentive regulation and investment: Evidence from European energy utilities. Journal of Regulatory Economics, 38, 1-26.

Cambini, C., \& Yiang, Y. (2009). Broadband investment and regulation: A literature review. Telecommunications Policy, 33, 559-574.

Carr, T. (2005). FERC's natural gas pipeline “open season” policy, memorandum to the transmission regulatory principles group (TREG).

Cleveland, W.S. (1979). Robust locally weighted regression and smoothing scatterplots. Journal of the American Statistical Association, 74(368), 829-836.

Cremer, H., Cremer, J., \& De Donder, P. (2006). Legal vs ownership unbundling in network industries. CEPR Discussion Paper no. 5767.

Denton, M., Rassenti, S., \& Smith, V. (2001). Spot market mechanism design and competitivity issues in electric power. Journal of Economic Behavior and Organization, 44, 435-453.

Draaisma, T., \& Noussair, C. (1997). Optimal bidding in a uniform price auction with multi-unit demand. Economics Letters, 157-162

ERGEG. (2008). Draft guidelines on article 22: An ERGEG public consultation paper. E07-GFG-31-07.

ERGEG. (2009). European regulators' experience with article 22 exemptions of directive 2003/55/EC 2008: Update of ERGEG's internal survey. Report E08-GIF-02-03.

European Union. The European Parliament and the European Council. (2003). Directive 2003/55/EC concerning common rules for the internal market in natural gas and repealing Directive 98/30/EC. Official Journal of the European Union, L176/57. 
Fischbacher, U. (2007). z-tree: Zurich toolbox for ready-made economic experiments. Experimental Economics, 10(2), 171-178.

Fluxis. (2010). Annual financial report. http://www.goo.g1/0Ff3F. Accessed on October 2011.

Fréchette, G. R. (2007). Session-effects in the laboratory. Working paper, New York University.

Gans, J., \& King, S. (2003). Access holidays for network infrastructure investment. Agenda, 10(2), 163178.

Gans, J., \& King, S. (2004). Access holidays and the timing of infrastructure investment. Economic Record, 80, 89-100.

Grether, D., Isaac, R. M., \& Plott, C. (1981). The allocation of landing rights by unanimity among competitors. American Economic Review, 71, 166-171.

Guthrie, G. (2006). Regulating infrastructure: The impact on risk and investment. Journal of Economic Literature, 44, 925-972.

Hogan, W. (1992). Contract networks for electric power transmission. Journal of Regulatory Economics, 4(3), 221-242.

Hogan, W., Rosellón, J., \& Vogelsang, I. (2010). Toward a combined merchant-regulatory mechanism for electricity transmission expansion. Journal of Regulatory Economics, 38(2), 113-143.

Holmberg, P. (2011). Strategic forward contracting in the wholesale electricity market. Energy Journal, 31, 169-202.

IEA. (1999). World energy outlook. International Energy Agency, http://www.iea.org/textbase/nppdf/ free/2009/WEO2009.pdf. Accessed on October 2011.

Joskow, P., \& Tirole, J. (2000). Transmission rights and market power on electric power networks. Rand Journal of Economics, 31(3), 450-487.

Joskow, P. (2005). Incentive regulation in theory and practice: Electricity distribution and transmission networks. AEI-Brookings Joint Center Working Paper No. 05-18.

Joskow, P., \& Tirole, J. (2005). Merchant transmission investment. Journal of Industrial Economics, 53(2), 233-264.

Kench, B. (2004). Let's get physical! Or financial? A study of electricity transmission rights. Journal of Regulatory Economics, 25, 187-214.

Kiesling, L., \& Wilson, B. (2007). An experimental analysis of the effects of automated mitigation procedures on investment and prices in wholesale electricity markets. Journal of Regulatory Economics, 31, 313-334.

Klumpp, T., \& Su, X. (2010). Open access and dynamic efficiency. American Economic Journal: Microeconomics, 2, 64-96.

Krichene, N. (2002). World crude oil and natural gas: A demand and supply model. Energy Economics, 24(6), 557-576.

Kristiansen, T., \& Rosellón, J. (2006). A merchant mechanism for electricity transmission expansion. Journal of Regulatory Economics, 29, 167-193.

Krogmeier, J., Menkhaus, D., Phillips, O., \& Schmitz, J. (1997). An experimental economics approach to analyzing price discovery in forward and spot markets. Journal of Agricultural and Applied Economics, 29, 327-336.

Léautier, T. (2000). Regulation of an electric power transmission company. The Energy Journal, 24(1), 61-92.

Le Coq, C., \& Orzen, H. (2006). Do forward markets enhance competition? Experimental evidence. Journal of Economic Behavior and Organization, 61, 415-431.

Macolm, J., \& Olsen, W. (2011). Fueling the price of power (and gas): The rising profitability of pipelines and the need for collective action. The Electricity Journal, 24(5), 7-13.

McCabe, K., Rassenti, S., \& Smith, V. (1989). Designing smart computer assisted markets: An experimental auction for gas networks. European Journal of Political Economy, 5, 259-275.

McCabe, K., Rassenti, S., \& Smith, V. (1990). Auction design for composite goods: The natural gas industry. Journal of Economic Behavior and Organization, 14, 127-149.

Nagel, T., \& Rammerstorfer, M. (2008). Price cap regulation and investment behavior-How real options can explain underinvestment. Journal of Energy Markets 1, (4).

Normann, H.-T., \& Ricciuti, R. (2009). Experiments for economic policy making. Journal of Economic Surveys, 23(3), 407-432.

Noussair, C. N., Pfajfar, D., \& Zsiros, J. (2011). Frictions, persistence, and central bank policy in an experimental dynamic stochastic general equilibrium economy. Working paper, Tilburg University. 
Oxera. (2011). Cost of capital for GTS, annual estimates from 2006 onwards. Report prepared for the NMa, http://www.nma.nl/images/Cost\%20of\%20capital22-187985.pdf. Accessed on October 2011.

Phillips, O., Menkhaus, D., \& Krogmeier, D. (2001). Laboratory behavior in spot and forward auction markets. Experimental Economics, 4, 243-256.

PJM. (2009). Financial transmission rights, PJM Manual 06. http://pjm.com/documents/manuals.aspx. Accessed on October 2011.

Rassenti, S., Smith, V., \& Wilson, B. (2003a). Controlling market power and price spikes in lelectricity networks: Demand-side bidding. Proceedings of the National Academy of Sciences, 100, 2998-3003.

Rassenti, S., Smith, V., \& Wilson, B. (2003b). Discriminatory price auctions in electricity markets: Low volatility at the expense of high price levels. Journal of Regulatory Economics, 23, 109-123.

Rosellón, J. (2003). Different approaches towards electricity transmission expansion. Review of Network Economics, 2(3), 238-269.

Spanjer, A. (2008). Do Article 22 exemptions adequately stimulate investments in European gas markets?. Zeitschrift für Energiewirtschaft, 32(1), 46-51.

Staropoli, C., \& Jullien, C. (2006). Using laboratory experiments to design efficienct market institutions: The case of wholesale electricity markets. Annals of Public and Cooperative Economics, 77, 555-577.

Vogelsang, I. (2001). Price regulation for independent transmission companies. Journal of Regulatory Economics, 20(2), 141-165.

Vogelsang, I. (2010). Incentive regulation, investments and technological change. CESifo Working Paper Series no. 2964.

von Hirschhausen, C. (2008). Infrastructure, regulation, investment and security of supply: A case study of the restructured US natural gas market. Utilities Policy, 16(1), 1-10.

Von Hirschhausen, C., \& Neumann, A. (2008). Long-term contracts and asset specificity revisited: An empirical analysis of producer-importer relations in the natural gas industry. Review of Industrial Organization, 32(2), 131-143.

Vossler, C., Mount, T., Thomas, R., \& Zimmerman, R. (2009). An experimental investigation of soft price caps in uniform price auction markets for wholesale electricity. Journal of Regulatory Economics, 36, 44-59.

Williamson, D., Jullien, C., Kiesling, L., \& Staropoli, C. (2006). Investment incentives and market power: An experimental analysis. Economic analysis group discussion paper, United States Department of Justice. 